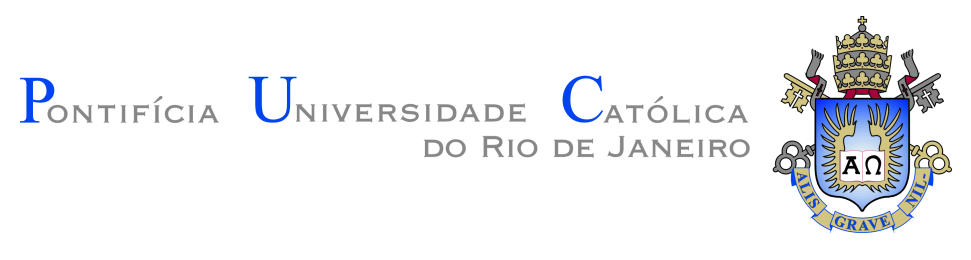

Felipe Van de Sande Araujo

\title{
Estimando a Curva Forward de Energia Elétrica no Brasil com um Modelo de Dois Agentes Utilizando Contratos por Diferença e Função ECP_G
}

Dissertação apresentada como requisito parcial para a obtenção do grau de Mestre pelo Programa de Pós-graduação em Administração de Empresas da PUC-Rio.

Orientador: Prof. Leonardo Lima Gomes 


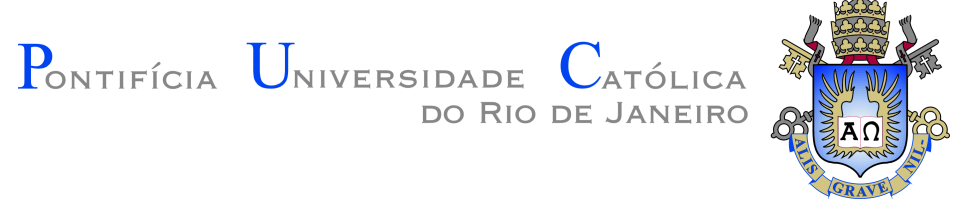

Felipe Van de Sande Araujo

\title{
Estimando a Curva Forward de Energia Elétrica no Brasil com um Modelo de Dois Agentes Utilizando Contratos por Diferença e Função ECP_G
}

\begin{abstract}
Dissertação apresentada como requisito parcial para a obtenção do grau de Mestre pelo Programa de Pós-graduação em Administração de Empresas da PUC-Rio. Aprovada pela Comissão Examinadora abaixo.
\end{abstract}

Prof. Leonardo Lima Gomes

Orientador

Departamento de Administração - PUC-Rio

Prof. Luiz Eduardo Teixeira Brandão

Departamento de Administração - PUC-Rio

Dra. Cristina Pimenta de Mello Spineti Luz

Diferencial Energia - Comercializadora de Energia e Projetos 
Todos os direitos reservados. É proibida a reprodução total ou parcial do trabalho sem autorização da universidade, do autor e do orientador.

Felipe Van de Sande Araujo

Bacharel em ciências econômicas pela Universidade Federal do Rio de Janeiro.

Ficha Catalográfica

Araujo, Felipe Van de Sande

Estimando a Curva Forward de Energia Elétrica no Brasil com um Modelo de Dois Agentes Utilizando Contratos por Diferença e Função ECP_G / Felipe Van de Sande Araujo; orientador: Leonardo Lima Gomes. - 2020.

$64 \mathrm{f}$. : il. color. ; $30 \mathrm{~cm}$

Dissertação (mestrado) - Pontifícia Universidade Católica do Rio de Janeiro, Departamento de Administração, 2020.

Inclui bibliografia

1. Administração - Teses. 2. Curva Forward;. 3. Contratos por Diferença;. 4. Equivalente Certo;. 5. CVaR;. 6. Otimização.. I. Gomes, Leonardo Lima. II. Pontifícia Universidade Católica do Rio de Janeiro. Departamento de Administração. III. Título. 
Dedico este trabalho aos meus mentores. Àqueles que me aprimoraram o pensar, e me permitiram desafiar e construir o conhecimento. 


\section{Agradecimentos}

Ao meu orientador professor Leonardo Lima Gomes cuja intuição e o conhecimento foram essenciais para a realização deste trabalho.

Ao CNPq e à PUC-Rio, pelos auxílios concedidos, que permitem que o esforço de inovar seja o foco único e principal do pesquisador.

Para Elisa, Ana Flor, Brigitte e Solange que contribuíram cada qual à sua maneira para que eu me dedicasse a esta pesquisa e por isso são sua matéria prima.

Para Antonio e Vinicius que me deram inspiração, no passado e para o futuro.

À Cristina Luz, cujo trabalho original foi fundamental para esta pesquisa.

Ao professor Luiz Brandão pelo apoio à minha formação como profissional de pesquisa, e aos demais participantes do NUPEI pelo companheirismo e disponibilidade.

Aos colegas, professores e funcionários do IAG PUC-Rio.

Aos professores que participaram da Comissão examinadora.

A todos os amigos e familiares por tornarem minha vida melhor ou mais interessante.

Agradeço ao programa de P\&D Aneel e à empresa Queiroz Galvão Energia, patrocinadora no âmbito do programa.

O presente trabalho foi realizado com apoio da Coordenação de Aperfeiçoamento de Pessoal de Nível Superior - Brasil (CAPES) - Código de Financiamento 001. 


\section{Resumo}

Araujo, Felipe Van de Sande; Gomes, Leonardo Lima. Estimando a Curva Forward de Energia Elétrica no Brasil com um Modelo de Dois Agentes Utilizando Contratos por Diferença e Função ECP_G. Rio de Janeiro, 2020. 64p. Dissertação de Mestrado - Departamento de Administração, Pontifícia Universidade Católica do Rio de Janeiro.

O desenvolvimento de métodos simples e efetivos para estimar o valor da curva forward de energia elétrica pode permitir que participantes do mercado precifiquem adequadamente suas posições especulativas ou defensivas. Uma ferramenta como esta poderia promover maior transparência para a definição dos preços futuros permitindo que os participantes do mercado futuro possam atuar com mais segurança e trazendo com isso um necessário aumento de liquidez. Neste trabalho apresento um modelo com dois agentes representativos que administram sua exposição ao risco através de um contrato por diferenças entre o preço futuro esperado da energia elétrica na região Sudeste no Brasil e um preço de referência. Demonstra-se que este mecanismo pode abranger todos os participantes do mercado, quer sejam especuladores ou agentes envolvidos na comercialização. A função de utilidade de cada participante é modelada utilizando uma versão Generalizada da Preferência CVaR Estendida (ECP_G) e o equilíbrio nesta transação é obtido através da minimização da diferença quadrática do equivalente certo destes agentes. Os resultados obtidos são comparados às previsões de mercado feitas por especialistas para o mesmo período e demonstram aderência dentro e fora da amostra.

\section{Palavras-chave}

Curva Forward; Contratos por Diferença; Equivalente Certo; CVaR; Otimização. 


\section{Abstract}

Araujo, Felipe Van de Sande; Gomes, Leonardo Lima (Advisor). Obtaining the Forward Curve for the Brazilian Power Market in a Dual Agent Model with Contracts for Difference and ECP_G Functional. Rio de Janeiro, 2020. 64p. Dissertação de Mestrado - Departamento de Administração, Pontifícia Universidade Católica do Rio de Janeiro.

The development of simple and effective mechanisms to estimate the value of the forward curve of power could enable market participants to better price hedging or speculative positions. This could in turn provide transparency in future price definition to all market participants and lead to more safety and liquidity in the market for electricity futures and power derivatives. This work presents a model for two market participants, a buyer and a seller of a contract for difference on the future spot price of electricity in southwest Brazil. It is shown that this model is representative of all market participants that have exposure to the future price of power. Each participant's utility function is modelled using a Generalized Extended CVaR Preference (ECP_G) and the market equilibrium is obtained through the minimization of the quadratic difference between the certainty equivalent of both agents. The results are compared with prediction of the future spot price of power made by market specialists and found to yield reasonable results when using out of sample data.

\section{Keywords}

Forward Curve; Contracts for Differences; Certainty Equivalent; CVaR; Otimization. 


\section{Sumário}

1 Introdução $\quad 15$

1.1 Contextualização 17

$\begin{array}{lll}1.2 & \text { Objetivos e estrutura } & 19\end{array}$

2 Revisão de Literatura $\quad 21$

3 Metodologia 31

3.1 Contratos por Diferença 31

3.2 Demonstração de que o modelo abrange todos os participantes do mercado 33

3.3 Dados utilizados 35

3.4 Desenho do modelo 35

$4 \quad$ Resultados e discussão $\quad 47$

4.1 Análise dos dados de preço spot futuro 47

4.2 Treinamento e validação do modelo para o algoritmo 1

4.3 Treinamento e validação do modelo para o algoritmo 2

4.4 Análise de sensibilidade dos parâmetros otimizados 55

5 Conclusão e trabalhos futuros $\quad 60$

6 Referências bibliográficas $\quad 62$ 


\section{Lista de figuras}

Figura 2.1 Citações e artigos indexados nas bases Web-of-Science e Scopus entre 2000 e 2014. Fonte: Weron, 2014. Tradução própria.

Figura 2.2 Função de utilidade dependente de probabilidade dada por uma medida CVaR para um nível de aversão ao risco $\alpha$. Fonte: Street et al., 2009.

Figura 2.3 Função de utilidade subjacente à medida ECP_G com N=2. Fonte: Luz, 2016.

Figura 3.1 Fluxograma de treinamento do algoritmo 1. Fonte: Elaboração Própria.

Figura 3.2 Fluxograma de validação do algoritmo 1. Fonte: Elaboração

Própria.

Figura 3.3 Fluxograma de treinamento do algoritmo 2. Fonte: Elaboração Própria.

Figura 3.4 Fluxograma de validação do algoritmo 2. Fonte: Elaboração Própria.

Figura 4.1 Distribuição de preços spot esperados por mês para o ano de 2020 - Dados de janeiro/2019. Fonte: Elaboração Própria.

Figura 4.2 Distribuição de preços spot esperados por mês para o ano de 2021 - Dados de janeiro/2019. Fonte: Elaboração Própria.

Figura 4.3 Distribuição de preços spot esperados por mês para o ano de 2020 - Dados de agosto/2019. Fonte: Elaboração Própria.

Figura 4.4 Histograma de preços spot esperados para janeiro (esq.) e dezembro (dir.) de 2020 - Dados de agosto/2019. Fonte: Elaboração Própria. 49 Figura 4.5 Função de utilidade subjacente à medida ECP_G para o vendedor. Fonte: Elaboração Própria.

Figura 4.6 Função de utilidade subjacente à medida ECP_G para o comprador. Fonte: Elaboração Própria.

Figura 4.7 Análise do VPL e equivalente certo para cada nível de preço de contrato. Fonte: Elaboração Própria.

Figura 4.8 Preços de equilíbrio mensal para 2020 e 2021 calculados a partir dos dados de treinamento e validação. Fonte: Elaboração Própria.

Figura 4.9 Preço de equilíbrio mensal para 2020 calculado a partir dos dados de validação. Fonte: Elaboração Própria.

Figura 4.10 Sensibilidade para $\lambda_{1}$ (esq.) e $\lambda_{2}$ (dir.) do comprador e do vendedor - Dados de janeiro/2019. Fonte: Elaboração Própria.

Figura 4.11 Sensibilidade para $\lambda$ do comprador no modelo com um único nível de risco - Dados de janeiro/2019. Fonte: Elaboração Própria.

Figura 4.12 Gráfico de superfície para $\lambda_{1}$ e $\lambda_{2}$ para o comprador (esq.) e o vendedor (dir.) - Dados de janeiro/2019. Fonte: Elaboração Própria.

Figura 4.13 Efeito de $\lambda_{C}$ e $\lambda_{V}$ sobre a média do PLD - Dados de janeiro/2019. Fonte: Elaboração Própria.

Figura 4.14 Sensibilidade para $\lambda$ e $\alpha$ no modelo com um único nível de risco - Dados de janeiro/2019. Fonte: Elaboração Própria. 
Figura 4.15 Sensibilidade para $\lambda_{2}$ e $\alpha 2$ do vendedor - Dados de janeiro/2019. Fonte: Elaboração Própria.

Figura 4.16 Sensibilidade do preço de equilíbrio para diferentes taxas de remuneração de capital. Dados de janeiro/2019 à esquerda e agosto/2019 à direita. Fonte: Elaboração Própria. 


\section{Lista de tabelas}

Tabela 3.1 Dados de entrada do modelo, por tipo, período e fonte.

Tabela 4.1 Preços forward e preço futuro anual médio usados no modelo. 49 Tabela 4.2 Parâmetros otimizados na calibração do algoritmo $1 \quad 49$

Tabela 4.3 Resultados financeiros da calibração do modelo 50

Tabela 4.4 Parâmetros otimizados na calibração do algoritmo 2

Tabela 4.5 Resultados da validação dos algoritmo 1 e 2 - preços de equilíbrio em $\mathrm{R} \$ / \mathrm{MWh}$

Tabela 4.6 Erros de estimativa do preço médio de equilíbrio para o preço forward em percentual. 


\section{Lista de algoritmos}

Algoritmo 1 Determinação do equilíbrio utilizando o VPL 41

Algoritmo 2 Determinação do equilíbrio mensal no modelo resumido 46 


\section{Lista de símbolos}

CCEE - Câmara de Comercialização de Energia Elétrica

CfD - Contracts for Difference

CMO - Custo Marginal de Operação

CVaR - Conditional Value at Risk

ECP - Extended CVaR Preference

ECP_G-Generalized Extended CVaR Preference

ONS - Operador Nacional do Sistema

PDUF - Probability Dependent Utility Function

PLD - Preço de Liquidação de Diferenças

PLUF - Piecewise Linear Representation of Utility Functions

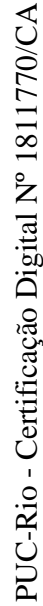

SIN - Sistema Interligado Nacional

VaR - Value at Risk

VPL - Valor Presente Líquido 
"avidya kshetram uttaresham" Ignorance is the breeding ground of all other [life afflictions]

Pátañjali, Yoga Sutra, II Sūtra 4. 


\section{1 \\ Introdução}

O preço futuro da energia elétrica é de difícil determinação, dada a própria natureza deste ativo. Para a maioria das commodities estocáveis o preço futuro pode ser determinado por uma relação de arbitragem utilizandose as taxas de juros, de conveniência e o custo de estocagem do ativo. No caso da eletricidade as tecnologias de armazenamento existentes não permitem que se acumule a energia por longos períodos e em grande quantidade, impossibilitando desta maneira o uso da relação de arbitragem como balizador financeiro do preço futuro.

Diferentes soluções para este problema podem ser encontradas, dentre elas a utilização do custo de armazenamento dos insumos utilizados na produção de eletricidade, que por possuírem dinâmica própria de preços emprestam às projeções seus próprios vieses (Routledge et al., 2001). Uma elegante solução para a determinação do preço futuro da eletricidade parte de um mecanismo de equilíbrio de mercado utilizando as preferências dos participantes (Bessembinder \& Lemmon, 2002). No referido artigo os autores modelaram os determinantes da preferência de cada agente diretamente envolvido no mercado, vendedor ou comprador de energia, em função da média e do risco de suas receitas.

No Brasil o exercício de estimar o preço futuro da eletricidade encontra também como obstáculo a ausência de um mercado aberto para a transação deste produto. A maioria das transações ocorre na forma de contratos diretos, fechados entre os agentes investidos no mercado, grandes produtores e distribuidores (Luz et al., 2012). Em função disso o preço futuro utilizado nas transações é calculado por empresas especializadas utilizando metodologias de pesquisa de mercado através da opinião de especialistas. Esta abordagem traz informação relevante e serve para fundamentar decisões de investimento e proteção para os agentes que estão (ou desejam estar) expostos ao preço futuro da eletricidade. Em contrapartida os métodos utilizados para a composição destas previsões não podem ser replicados de maneira independente, ou mesmo aplicados em modelos matemáticos de previsão.

Neste trabalho será examinado um modelo teórico que se baseia no artigo seminal de Bessembinder e Lemmon (2002) e busca encontrar um preço de equilíbrio entre os agentes de mercado que possa ser utilizado como uma aproximação para o preço futuro da energia elétrica. Para conferir abrangência ao modelo e incorporar a participação dos agentes especulativos, bem como dos 
envolvidos diretamente no mercado de energia, será utilizado o contrato por diferenças (CfD), um derivativo financeiro de ampla utilização e fácil cálculo de resultado que será analisado na seção inicial do capítulo de metodologia. Partindo das equações para o cálculo do resultado do CfD será demonstrado que esta ferramenta pode ser utilizada para modelar as necessidades de proteção ou exposição de todos os participantes do mercado.

Como não é possível reconstruir o processo decisório feito por especialistas, que contam com sua própria experiência para compor suas expectativas, o modelo será fundamentado no principal componente utilizado por todos os participantes para suas projeções: as séries de preço de liquidação de diferenças (PLD) fornecido pela Câmara de Comercialização de Energia Elétrica (CCEE) que são calculados com base nos dados de saída do modelo de despacho centralizado do Operador Nacional do Sistema (ONS) (CCEE, 2019). Em economias cuja a geração é predominantemente hídrica e que utilizam ferramentas de otimização do custo de operação, como ocorre no Brasil, os preços estimados podem ser utilizados como referência para o preço spot esperado da eletricidade (Fleten \& Lemming, 2003). Assim o modelo desenvolvido neste trabalho parte da premissa que é possível obter valores aderentes ao estimado pelos agentes do mercado utilizando como fonte de informação os preços spot esperados fornecidos pelo modelo Newave-Decomp. Estes preços não incorporam, no entanto, as preferências e a aversão ao risco dos agentes envolvidos em sua transação.

Com o intuito de incorporar nos preços futuros estimados os níveis distintos de preferência e aversão ao risco para cada agente será utilizado no modelo a medida Generalized Extended CVaR Preference, ou ECP_G (Luz, 2016), com dois níveis de aversão ao risco para o comprador e para o vendedor, ambas as partes representativas envolvidas na transação do CfD. O uso de uma medida alternativa se explica uma vez que as funções de utilidade clássicas apresentam limitações em seu uso por conta da complexidade em sua determinação e também devido ao fato de apresentar incongruências em regiões de alta riqueza e alta aversão ao risco (Klotzle et al., 2012). Uma visão geral da medida ECP_G será oferecida na seção final do capítulo seguinte. O cálculo do equilíbrio utilizando duas medidas de aversão ao risco possibilita alcançar valores compatíveis com os estimados pelos especialistas, como será apresentado no capítulo de resultados, em especial na seção de testes de sensibilidade do modelo. 


\section{Contextualização}

O Brasil é um país de dimensões continentais e isso constitui um desafio para o funcionamento de um sistema de geração, transmissão e distribuição de eletricidade. Até o final do século XX a indústria de energia elétrica era administrada pelo estado, com exceção de pequenos fornecedores locais ou isolados. A liberalização da produção e comercialização se iniciou em 1997 com a Reestruturação do Sistema Elétrico Brasileiro (RE-SEB), e o processo de abertura segue em desenvolvimento até o presente momento (Fernandes et al., 2018).

Apesar de ter um território de 8,5 milhões de quilômetros quadrados o Brasil tem a grande maioria de suas cidades e distritos conectados ao sistema interligado nacional (SIN), restando apenas 1,7\% da geração de eletricidade em sistemas isolados. Como qualquer sistema de transmissão de proporções continentais, a rede de transmissão do SIN possui limites físicos que podem ocasionar gargalos no fornecimento de eletricidade e por isso não é incomum haver preços diferentes dentro dos principais sub-mercados, a saber os mercados do Norte, Nordeste, Sul e Sudeste/Centro-Oeste, sendo este último o responsável pela maioria do consumo nacional (EPE, 2019).

Por fonte, a maior participação na geração de eletricidade é a de origem hidroelétrica, que corresponde a 66,6\% da geração nacional, segundo o Balanço Energético Nacional de 2019. As usinas variam de porte e tamanho e podem ser pequenas centrais locais ou usinas à fio d'água, ou mesmo grandes projetos de impacto regional ou internacional como as usinas de Belo Monte e Itaipu. As demais fontes de geração elétrica na matriz brasileira são: plantas termoelétricas, que correspondem a $25,2 \%$ da geração total, sendo especificamente $8,6 \%$ por plantas que utilizam gás natural como combustível, 8,5\% originários da queima de biocombustíveis ou refugos agriculturais, $3,2 \%$ de usinas abastecidas com carvão mineral (na região Sul do país), 2,5\% a partir de duas usinas eletronucleares e os 2,4\% restantes abastecidas por óleo combustível. Atualmente o Brasil conta ainda com 8,2\% de sua geração elétrica advinda de fontes alternativas e renováveis como solar, eólica e da energia das ondas ou marés.

Por conta da predominância da energia de origem hídrica é adotado o controle centralizado do despacho para buscar uma solução eficiente, que evite o desperdício no armazenamento de água, assegurando a viabilidade econômica dos projetos ao mesmo tempo que maximiza a segurança no abastecimento energético. O Operador Nacional do Sistema utiliza um software para a minimização do custo marginal de operação do sistema elétrico, gerando cenários de hidrologia e aplicando-os na matriz de geração e distribuição nacional de modo a fazer com que o despacho de usinas termoelétricas - que 
possuem maior custo de operação - seja o menor possível (Pelajo et al., 2019). Este pacote de computação chama-se Newave-Decomp e, embora os resultados das simulações utilizadas pelo ONS estejam disponíveis publicamente, só é possível utilizar-los se o software estiver disponível. Alguns resultados podem ser cedidos com fins de pesquisa por participantes do mercado que tenham acesso ao sistema, como é o caso dos dados obtidos neste trabalho.

O segmento de distribuição de energia elétrica também pertencia ao controle estatal até o final da década de 1990, quando um processo de descentralização teve início, com o objetivo de sanar um ambiente de escassez de investimentos no setor. No ano de 1998 a reestruturação do setor elétrico foi concluída apresentando diretrizes para a desverticalização e aumento de competitividade. Este processo foi interrompido prematuramente no início da década seguinte devido a uma crise no abastecimento de eletricidade de proporções nacionais que provocou mudanças emergenciais que foram transformadas em lei em 2004, consolidando um mercado livre para a transação de energia elétrica (Luz et al., 2012).

Atualmente o mercado de eletricidade pode ser dividido em dois segmentos: o de consumidores cativos, que são protegidos pelo mercado regulado onde o custo da eletricidade segue determinação legal, e consumidores livres, que podem adquirir eletricidade através de contratos diretos com geradores, quer sejam de longo prazo de fornecimento, ou diretamente no mercado de curto prazo, onde o valor é formado pelo preço de liquidação de diferenças, de caráter extremamente volátil.

O mercado de derivativos de energia elétrica é ainda muito restrito, face ao potencial de consumo e fornecimento do país. Muitas transações são realizadas diretamente entre grandes participantes do mercado, em contratos bilaterais ou através de derivativos de balcão. O preço de referência utilizado nestas transações não é visível para o restante do mercado. Nos anos de 2005 e 2006 a então existente Bolsa de Valores do Rio de Janeiro (BVRJ) ofereceu em sua plataforma a transação de contratos de eletricidade, no entanto devido à baixa procura o serviço foi suspenso.

Os derivativos de energia são importantes no mercado brasileiro em função da prevalência de contratos de longo prazo que obrigam geradores que podem estar expostos à flutuação de condições de oferta a comprar energia a preço de mercado no caso em que não possam cumprir suas obrigações (Fernandes et al., 2019).

A formação de preço de derivativos em mercados tradicionais é lastreada em último caso por uma relação de arbitragem entre seu valor futuro e o custo de comprar o ativo e estocá-lo para futura entrega (Hull, 2013). 
No caso da eletricidade, no entanto, a armazenagem de longo prazo não é comercialmente viável, o que deixa o preço futuro à mercê das flutuações de demanda e oferta do mercado. É possível realizar a estocagem de insumos para a produção de eletricidade no curto prazo, como por exemplo deixar de utilizar água em reservatórios de hidroelétricas ou mesmo estocar combustível para abastecer termoelétricas. No entanto isso adiciona a complexidade advinda da disponibilidade destas fontes aos preços futuros.

Por conta da iliquidez e falta de transparência nas transações de hedge existentes, e por conta da própria natureza do produto eletricidade, não há uma fonte única de dados que ofereça um valor para o preço futuro da eletricidade. Atualmente algumas empresas de pesquisa se dedicam a obter a opinião de profissionais qualificados e compor uma estimativa generalizada para os quatro sub-mercados brasileiros (DCide, 2018). Muito embora estes valores sejam amplamente divulgados e a metodologia utilizada para a formação dos preços seja transparente, o processo de formação da curva forward depende da informação de especialistas e não é replicável a partir de dados de preço somente.

Um sistema onde o despacho é majoritariamente hidroelétrico e centralizado, como no mercado Nórdico ou no Brasil, as simulações de preço a partir de cenários de hidrologia são costumeiramente usadas como base de referência para a formação de preços futuros (Luz et al., 2012). É seguro assumir que os participantes do mercado brasileiro de energia elétrica tenham acesso a estes dados e gerem suas expectativas com base nesta informação. Por outro lado é preciso levar em consideração que modelos de otimização como o NewaveDecomp não incluem o prêmio de risco dos agentes em seus cálculos de preço spot esperado e, portanto, estes dados não devem ser utilizados diretamente para a formação de preço futuro de eletricidade ou de seus derivativos.

\section{2}

\section{Objetivos e estrutura}

O objetivo deste trabalho é apresentar um modelo que utilize os dados amplamente disponíveis pelos participantes do mercado e construa uma estimativa para o preço forward de eletricidade a partir do equilíbrio entre o equivalente certo dos agentes representativos em uma transação de contratos por diferença. Especificamente, pretende-se oferecer:

1. Uma demonstração teórica de que o modelo proposto é abrangente para todos os participantes do mercado; 
2. Uma aplicação prática do modelo descrito utilizando dados reais e estimativas de preço forward, bem como uma análise dos erros de estimativa quando comparada à previsão dada por especialistas;

3. Uma formulação analítica para a obtenção do preço de equilíbrio do modelo;

4. Os algoritmos destas implementações do modelo, de modo que estes possam ser facilmente replicáveis.

Ao atingir os objetivos enumerados acima, este modelo pode ser utilizado para a confecção de previsões não viesadas dos preços futuros, após a realização de um estudo empírico mais robusto para a correta estimação dos seus parâmetros. Busca-se com este trabalho oferecer o arcabouço analítico para iniciar a construção de uma linha de referência ampla e global, baseada em modelos matemáticos puros, para o preço futuro de eletricidade no mercado brasileiro. Este mecanismo pode ser adaptado para uso em softwares de negociação, bolsas e até mesmo oferecer um balizador contra eventuais manipulações de mercado.

Mesmo que o modelo desenvolvido seja simples e não pretenda ser extensivo e abrangente, ainda assim atinge o objetivo proposto. Ao demonstrar que é possível obter, utilizando o modelo aqui desenvolvido, valores para a curva forward que são aderentes aos valores oferecidos por especialistas no mercado, acredito estar oferecendo uma metodologia sistemática, transparente e de fácil execução, com benefício para todos que, direta ou indiretamente, estão expostos ao preço futuro da eletricidade.

Este trabalho segue o formato tradicional de uma dissertação de mestrado e à essa introdução segue-se uma revisão de literatura onde serão analisados os principais artigos que servem de base teórica para este texto. No capítulo terceiro, de metodologia, estão delineadas as equações subjacentes ao cálculo dos contratos por diferença e do equilíbrio no modelo multi-agente para os dois algoritmos apresentados, o primeiro por otimização e o segundo analítico. O capítulo seguinte analisa os dados utilizados, bem como os resultados de cada algoritmo, durante o treinamento e suas validações, além de conter uma seção final com testes de sensibilidade para os parâmetros otimizados nos passos anteriores. Por fim conclui-se o trabalho com as considerações finais do autor. 


\section{2}

\section{Revisão de Literatura}

Uma extensa revisão bibliográfica de procedimentos de estimativa do preço futuro da eletricidade foi realizada por Weron (2014), classificando os métodos atualmente em uso na literatura nas seguintes categorias: multi-agent, fundamental, reduced-form, statistical e computational intelligence.

O autor demonstra através de pesquisa de artigos e citações presentes nas bases Web-of-Science e Scopus que este tópico "electricity price forecast"é um tema bastante recente com um número muito reduzido de publicações anteriores ao ano 2000. Os artigos publicados e citações, por ano em cada uma das bases, pode ser visto na figura 2.1.
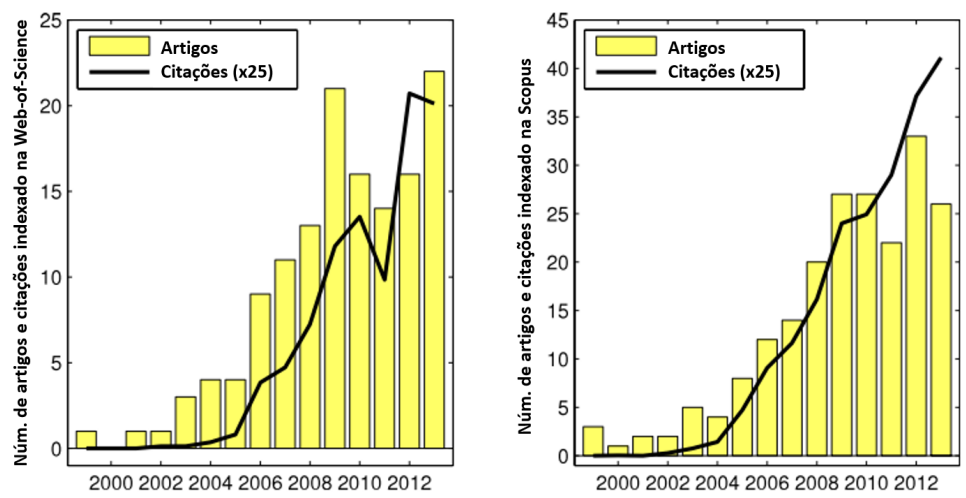

Figura 2.1: Citações e artigos indexados nas bases Web-of-Science e Scopus entre 2000 e 2014. Fonte: Weron, 2014. Tradução própria.

Como pode ser observado pelos números apresentados na figura 2.1, o estudo dos métodos de estimativa para o preço da energia elétrica é nascente e ainda não há consenso para um método definitivo. ${ }^{1}$ Em sua revisão, Weron afirma que os modelos que efetivamente podem estimar o preço da eletricidade são aqueles que lidam com o curto prazo, previsão para as horas ou o dia seguintes, ou médio prazo, prevendo um preço para as próximas semanas ou meses. Segundo sua avaliação, os modelos que estimam preço de eletricidade para longo prazo não se enquadram em sua revisão de literatura, pois são tipicamente utilizados para modelagem financeira de derivativos.

A principal base teórica na qual este trabalho se sustenta não está citada na revisão feita por Weron (2014). Utilizo como ponto de partida a publicação

\footnotetext{
${ }^{1}$ Anedoticamente, Weron menciona que os métodos de inteligência computacional são mais adotados por engenheiros de computação e estes frequentemente não possuem uma base teórica sólida em econometria. Por outro lado os modelos adotados por economistas, embora bem especificados, não lançam mão das tecnologias mais recentes de modelagem.
} 
seminal de Bessembinder \& Lemmon (2002), onde é formulado um modelo de equilíbrio entre os agentes do mercado para a estimativa do preço forward da eletricidade no longo prazo. Os autores explicam a principal dificuldade que existe na modelagem do preço forward da eletricidade: a característica de não-armazenamento do ativo subjacente. A tecnologia atual não permite o armazenamento comercial da eletricidade em grandes quantidades e por longo prazo. No mercado de eletricidade as possibilidades de armazenamento se restringem à estocagem de insumos para a sua produção no futuro.

O preço forward para ativos financeiros, ou para commodities estocáveis pode ser obtido usualmente através de uma relação de não-arbitragem entre o seu custo financeiro de armazenamento para a data futura e outros custos ou prêmios associados, como o prêmio de conveniência. Isso permite uma aproximação precisa para o preço do derivativo em uma data futura: se o preço estiver acima do valor do financeiro do armazenamento, os agentes racionais irão estocar o bem para obtê-lo na mesma data do derivativo.

Bessembinder \& Lemmon (2002) partem de um modelo para a estimativa do preço forward baseado na relação de oferta e demanda entre os agentes do mercado. Sua modelagem busca encontrar o equilíbrio entre a necessidade de produtores e distribuidores de eletricidade por contratos bilaterais de fornecimento, lastreados no preço forward. A formulação de seu modelo leva em conta os custos dos agentes e a maximização de seus resultados financeiros. Através de um rearranjo algébrico o preço de equilíbrio é obtido como uma composição do valor esperado do preço spot futuro, da variância e da assimetria de sua distribuição, conforme observado na equação 2-1 a seguir.

$$
P_{F}=E\left[P_{W}\right]+\alpha \times \operatorname{Variancia}\left[P_{W}\right]+\gamma \times \text { Assimetria }\left[P_{W}\right]
$$

Onde $P_{F}$ é o preço forward de equilíbrio, $P_{W}$ é o preço spot futuro que é estocástico, $E[$.$] é o operador de valor esperado, \alpha$ e $\gamma$ são parâmetros do modelo definidos a partir das características econômicas dos agentes.

Esta equação permite tecer conclusões a respeito da diferença entre o preço spot futuro e o preço forward, mais especificamente, que o preço forward será distinto do valor esperado do preço spot futuro de acordo com parâmetros de utilidade dos agentes $(\alpha$ e $\gamma$ ) e medidas de risco do preço spot futuro (variância e assimetria). De acordo com as especificações do modelo o parâmetro $\gamma$ tem valor estritamente positivo, logo o preço forward será diretamente proporcional à assimetria na distribuição dos preços spot futuros e será mais elevado quando a assimetria for positiva. 
Os autores explicam que a assimetria no preço spot futuro é um reflexo da convexidade nos custos de produção da eletricidade, por conta das diferentes tecnologias utilizadas para a produção, e também pode ser um reflexo de flutuações da demanda. Logo é esperado que exista uma diferença entre o preço forward e o preço spot futuro esperado, que é o prêmio de risco da eletricidade. O sinal e a medida do prêmio de risco dependem, além da assimetria, da varância esperada para o preço spot futuro.

A conclusão do artigo menciona que o fato do preço forward ser distinto do preço spot esperado denota também uma pequena participação de investidores especuladores no mercado de energia, que poderiam corrigir as distorções previsíveis que ocorrem por flutuações sazonais de demanda. Esta baixa participação é explicada por um alto custo para participar do mercado ou pela falta de um preço de referência futura acessível para todos os participantes.

Uma limitação implícita no modelo de Bessembinder \& Lemmon é a restrição do modelo à participação dos investidores especuladores. O modelo acima é especificado para um mercado onde apenas os produtores e consumidores de energia participam.

Outro artigo que serve de base para este trabalho é a pesquisa de Fleten \& Lemming (2003) para a construção de uma curva para o preço forward da energia elétrica no mercado comum do norte europeu (Nordpool), que foi classificado como um modelo preditivo em forma reduzida (reduced-form model) (Weron, 2014). Para a modelagem da curva forward foram utilizados como base os preços de contratos à termo disponíveis para diferentes datas neste mercado. Como estes contratos abrangem muitos períodos e frequentemente são firmados em preços médios que não observam os regimes sazonais, para que estes dados sejam traduzidos em um modelo único de previsão de preços futuros, os dados de contratos forward foram associados a um modelo de previsão de preços spot do tipo bottom-up em um modelo de previsão estocástico do tipo LSQ (constrained least square) combinado com um modelo de interpolação suave que tem por objetivo remover saltos na previsão.

O modelo é testado em um conjunto de dados obtidos do mercado escandinavo e obtém resultados satisfatórios, produzindo uma curva forward com alto nível de detalhamento, ou seja, preços distintos para diferentes períodos no futuro. Esse detalhamento é obtido por associar os preços de saída do modelo MPS de despacho centralizado naquele mercado, cobrindo a lacuna dos dados de preço forward e oferecendo um comportamento sazonal ao modelo.

Os autores afirmam que os agentes especuladores, presentes no mercado, 
formam suas opiniões sobre as expectativas de preços futuros ao observar os dados dos modelos centralizados como o MPS, que possuem as vantagens de incluir um extensivo detalhamento sobre as capacidades de geração, transmissão e distribuição de energia, bem como considerar séries longas de hidrologia e preços de combustíveis e outros insumos para a fornecimento de eletricidade.

O trabalho de Fleten \& Lemming traz como contribuição a validação do uso de um modelo bottom-up de previsão de preço spot como fonte fidedigna de informação sobre o preço spot futuro. Em mercados elétricos com grande predominância de recursos hídricos, como ocorre na Noruega, são comuns os sistemas de despacho centralizados para a minimização do custo de operação do sistema e a garantia da segurança no abastecimento. Estes modelos são fontes de referência para o preço futuro no mercado de eletricidade.

Os autores alertam no entanto que estes modelos não bastam para criar uma aproximação do preço forward pois não incluem em seu cálculo os valores de aversão ao risco dos agentes do mercado. Por isso são utilizados para a obtenção da curva forward os modelos financeiros.

Também importante para este trabalho é o artigo escrito por Luz et al., (2012) que realiza uma análise do mercado brasileiro de contratos à termo de eletricidade, buscando obter um modelo de previsão da curva forward.

Os autores formulam um modelo financeiro de precificação de contratos à termo com base em valores descontados de risco e em tempo presente. Para obter a curva forward o modelo usa como base o valor presente dos contratos bilaterais obtidos no mercado e um conjunto de taxas de desconto livres de risco. O cálculo do valor presente dos contratos é dado pela equação 2-2 a seguir.

$$
V P_{C}=\sum_{i=n}^{N} \frac{P_{i C}}{\left(1+t_{i}\right)^{i}}
$$

Onde $V P_{C}$ é o valor presente do contrato, $n$ é o primeiro mês de entrega na amostra, $N$ é o último mês de entrega na amostra, $P_{i C}$ é o preço no mês i dado pelo contrato $\mathrm{C}$.

Obtendo-se uma matriz de valores presentes é possível projetar preços futuros usando para isso uma matriz de taxas de desconto com as dimensões correspondentes ao número total do conjunto de valor presente dos contratos bilaterais observados, e o número total de períodos a ser considerado. Este modelo tem a limitação que o número de períodos previstos é igual ou menor 
que o número de contratos bilaterais utilizados na sua confecção. Além disso, empiricamente foi observado que existem oportunidades de arbitragem no mercado que levam o determinante da matriz de taxas de desconto a ser nulo. O modelo segue incorporando um vetor de erros e a determinação dos preços de equilíbrio é feita por uma regressão linear.

O trabalho conclui-se com uma análise empírica dos prêmios de risco no mercado a termo de energia elétrica no Brasil, onde se observou predominantemente o comportamento de contango para a curva forward. Das limitações do trabalho foram sublinhadas pelos autores a falta de liquidez e transparência no mercado à termo brasileiro, o que torna difícil a obtenção de preços para a construção da curva de maneira detalhada. Os autores ainda explicitam que através do método proposto não pode ser comprovada a relação entre o preço spot, presente ou futuro, dados por resultados de PLD obtidos através do modelo centralizado de despacho no mercado brasileiro (Newave-Decomp) e o preço à termo da energia.

Um estudo anterior, feito por Benth et al. (2008), especifica um modelo de equilíbrio em um cenário multi-agente para obter o preço forward e o prêmio de risco de médio e longo prazo para o mercado elétrico alemão. Este modelo utiliza-se do princípio da equivalência certa (certainty equivalence principle) ${ }^{2}$ para estabelecer limites para o preço de equilíbrio, dadas funções de utilidade côncavas do tipo Von Neumann-Morgenstern para ambos os agentes, gerador e distribuidor de energia.

Os autores afirmam que os produtores tem incentivo financeiro para transacionar contratos bilaterais que sejam covariantes com sua receita, e, de modo análogo os consumidores também tem interesse em diversificar seus riscos. Aprofundando-se nesta análise, os geradores costumam estar expostos à incerteza por um tempo mais longo, provavelmente devido ao longo tempo de recuperação do investimento realizado nos seus ativos. Consumidores por outro lado parecem tomar decisões baseando-se em um intervalo de tempo mais curto.

Neste caso, os ganhos de diversificação de risco irão variar ao longo do tempo tanto para os consumidores quanto para os fornecedores, tendo impacto no preço de mercado. A conclusão do artigo é a de que estas diferentes preferências, ou níveis de aversão ao risco, explicam os diferentes sinais do prêmio de risco do mercado, e sua magnitude. Essas diferentes preferências

${ }^{2} \mathrm{O}$ princípio da equivalência certa é uma propriedade do controle estocástico e não deve ser confundido com o equivalente certo de um processo aleatório, este último sendo de maior interesse para esta dissertação. 
para a mitigação de risco irão determinar o que os autores denominam de poder de mercado (market power).

O modelo apresentado calcula o ponto de indiferença para ambos os agentes entre adquirir um contrato bilateral ou estar exposto ao preço spot. Em seguida são estabelecidos limites para o preço de equilíbrio baseando-se no princípio da equivalência certa. Desta maneira é estabelecido um conjunto de soluções possíveis para o equilíbrio, e o preço pode ser determinado dentro dos limites por um processo estocástico.

Na determinação dos parâmetros do modelo foram estabelecidos níveis de aversão ao risco maiores para o consumidor do que para o produtor. Os autores afirmam que a presença de saltos no preço spot futuro da eletricidade provoca uma maior aversão ao risco por conta dos consumidores contra subidas expressivas do preço da energia.

A conclusão do artigo traz a afirmação que a estrutura do prêmio de risco do mercado pode ser adequadamente modelada utilizando as premissas observadas de aversão ao risco e poder de mercado para os diferentes agentes no equilíbrio. Os dados do experimento empírico confirmam e reforçam a teoria apresentada.

Um artigo de Street et al. (2009) que utiliza-se de funções de utilidade do tipo CVaR (Conditional Value at Risk) ${ }^{3}$, procura especificar a curva de suprimento (Willing-to-Supply) do gerador de eletricidade em um leilão de fornecimento de longo prazo no mercado brasileiro de energia elétrica. Neste leilão a demanda é estática e a oferta é feita pelos geradores participantes. $\mathrm{O}$ preço é determinado de forma reversa, iniciando em um valor elevado e sendo reduzido com as sucessivas ofertas dos geradores.

O artigo apresenta uma estimativa da curva de suprimento do gerador de eletricidade através de dois modelos: o primeiro por uma função PLUF ( $P i$ ecewise Linear representation of Utility Functions), que particiona a função utilidade em diversos segmentos lineares, e o segundo através de uma combinação convexa do valor esperado do preço futuro da eletricidade obtido no leilão e uma medida de risco CVaR para a mesma variável.

Os autores explicam que os leilões são o mecanismo fundamental de expansão de capacidade de geração elétrica no Brasil, uma vez que o preço spot é muito volátil e não oferece o sinal correto para o investimento. Neste caso

${ }^{3} \mathrm{~A}$ medida $C V a R_{\alpha}$ é amplamente utilizada em análise de risco de derivativos (Schur et al., 2019) e consiste de uma média dos valores de uma distribuição abaixo de um determinado patamar dado pelo quantil $(1-\alpha)$. CVaR é uma medida de risco coerente e possui as características de ser convexa, positivamente homogênea, e invariante por translação (Uryasev, 2000, Rockafellar \& Uryasev, 2000, Pflug, 2000). VaR, Value-at-Risk é um valor da distribuição que corresponde a um quantil $(1-\alpha)$ (Jorion, 1996). 
os contratos bilaterais são um elemento chave, e estes contratos, sendo instrumentos financeiros, são diretamente relacionados aos contratos por diferenças. ${ }^{4}$ Embora os contratos bilaterais sejam apenas financeiros, estes devem obrigatoriamente estar atrelados a uma garantia de fornecimento, denominada lastro, que é emitida por um gerador, assegurando a segurança no abastecimento mesmo em períodos adversos (secos).

A construção da curva PLUF foi feita de forma detalhada, especificando um gerador teórico e diversos níveis de retorno no investimento que correspondem às expectativas do seu grupo administrativo (mesa diretora e departamento de risco). Assim cada segmento linear da função utilidade corresponde a um nível de retorno, que corresponde por sua vez a uma taxa de remuneração de capital diferente dada pelo risco deste retorno.

A medida combinada do valor esperado do preço futuro e o CVaR não requer tanto detalhamento, bastando que sejam especificados dois parâmetros: o nível de aversão ao risco dado pelo parâmetro $\alpha$ e o peso $\lambda$ que pondera a média entre o valor esperado e o CVaR. Desta medida obtém-se uma função de utilidade dependente de probabilidade (PDUF, Probability Dependent Utility Function). Esta função é côncava e seu gráfico pode ser observado na figura 2.2.

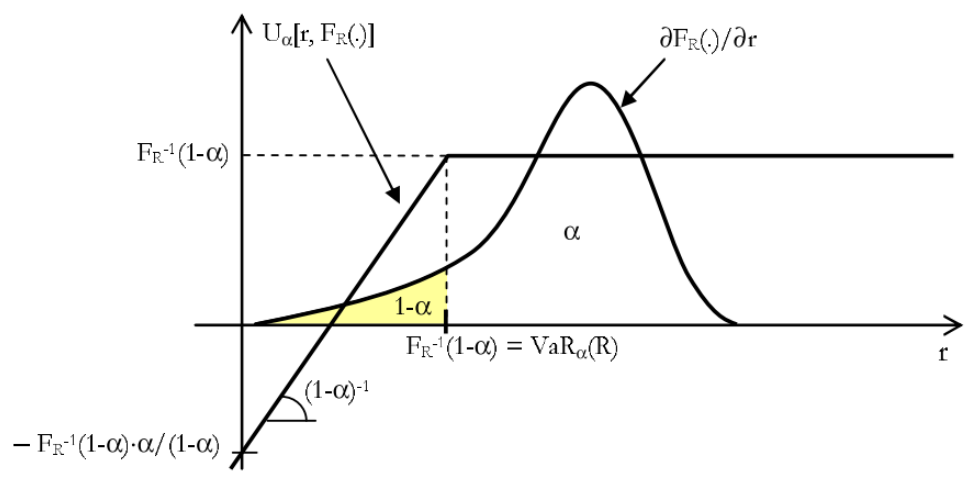

Figura 2.2: Função de utilidade dependente de probabilidade dada por uma medida CVaR para um nível de aversão ao risco $\alpha$. Fonte: Street et al., 2009.

O CVaR possui, segundo o artigo, diversas qualidades que explicam sua extensa adoção como medida de alocação de portfolio, que são a sua especificação intuitiva, suas medidas de coerência e sua capacidade de incorporar a aversão a perdas de alto impacto e baixa probabilidade.

Uma conclusão relevante apontada pelos autores sobre agentes que utilizam a combinação convexa de um valor esperado e uma medida CVaR é

${ }^{4}$ Contratos por Diferença (CfD) são contratos bilaterais utilizados como derivativos mundialmente em diferentes mercados, inclusive no setor elétrico (Brown et al., 2010). Este instrumento será analisado no capítulo de metodologia, a seguir. 
a possibilidade de obter o equivalente certo $^{5}$ como resultado direto da medida de utilidade, o que faz com que medidas descontadas por uma taxa ao longo do tempo sejam valores financeiros e não de utilidade.

Os autores atentam ainda para o fato de que uma medida de risco que busque penalizar cenários extremos não deveria ser calculada sobre o valor presente líquido dos cenários, pois estes podem apresentar variações no tempo que se compensem financeiramente. A correta aplicação seria utilizar a fórmula de aversão ao risco diretamente sobre cada período de modo a obter o resultado financeiro compensado pela utilidade para cada segmento e só então trazer toda a medida a valor presente.

Para o teste empírico foi especificado um modelo PLUF com cinco segmentos lineares, simbolizando a curva de suprimento de um gerador teórico que com capacidade de 100 MWmed. Para o mesmo gerador foi modelada uma combinação convexa utilizando o valor esperado do preço de energia e a medida CVaR para um nível $\alpha$ de $95 \%$ e um peso $\lambda$ de $50 \%$.

Os resultados demonstram que ambos os modelos possuem performance semelhante, mantendo a curva de oferta do gerador abaixo do máximo de sua capacidade, de modo a evitar o risco de não fornecimento em cenários extremos. A trajetória da curva de oferta também foi bastante similar entre os dois modelos. Os autores concluem o estudo apontando a possibilidade da utilização destes modelos para a análise das tarifas obtidas em leilões públicos de eletricidade, no que tange à saúde do mercado, dadas as atitudes dos geradores frente ao risco.

No ano seguinte Street (2010) publicou um artigo teórico aprofundando a especificação de uma medida de risco formada pela combinação convexa entre o valor esperado e uma medida CVaR. Esta medida combina a simplicidade de uma medida de risco linear ao mesmo tempo que provê uma estrutura côncava e é denominada ECP (Extended CVaR Preference). A fórmula da ECP é idêntica à utilizada no artigo anterior (Street et al., 2009) e pode ser vista na equação 2-3, a seguir.

$$
E C P_{\alpha, \lambda}=(1-\lambda) \times E[X]+\lambda \times C \operatorname{VaR} R_{\alpha}(X) ; \lambda \in[0,1]
$$

\footnotetext{
${ }^{5}$ Em um cenário de incerteza o risco calculado pela função utilidade pode ser expressado através de um número equivalente de unidades monetárias que torne o participante indiferente a receber este valor sem risco ou arriscar-se. Este montante é denominado o equivalente certo de um cenário aleatório. Como o equivalente certo é expresso em unidades monetárias o resultado pode ser comparado entre indivíduos que apresentam distintas funções de preferência ou aversão ao risco.
} 
Este artigo prova a coerência da medida de risco ECP através de suas características de invariância à translação, ser positivamente homogênea, superaditividade, monotonicidade e consistência. Prova também que o equivalente certo da medida ECP é o valor esperado da utilidade, e que a função é convexa nas probabilidades e avessa ao risco. Demonstra também que a medida ECP evita resultados paradoxais (e.g. paradoxo de Allais) que acometem modelos que utilizam o CVaR como única medida de risco.

Luz (2016) descreve em um dos capítulos de sua tese de doutorado uma nova medida de aversão ao risco, denominada ECP_G que é uma generalização da medida ECP (Street, 2010) para diferentes níveis de aversão ao risco.

A medida ECP_G oferece mais flexibilidade para o cálculo da utilidade, apresentando segmentos distintos de funções de utilidade linear para cada nível de aversão ao risco. Os parâmetros da função ECP_G são um peso $\lambda$ e um nível de aversão ao risco $\alpha$ para cada um $\operatorname{dos} n$ segmentos que a constituem. A forma generalizada para $n$ níveis de aversão ao risco da função de utilidade ECP_G pode ser descrita pela equação 2-4.

$$
\begin{array}{r}
E[U(X)]=\lambda_{0} \times E[X]+\sum_{n=1}^{N}\left[\lambda_{n} \times C \operatorname{VaR} R_{\alpha_{n}}(X)\right] \\
\text { Onde }: \sum_{n=0}^{N} \lambda_{n}=1
\end{array}
$$

A Figura 2.3 mostra o comportamento da função de utilidade subjacente à medida ECP_G para dois níveis de aversão ao risco.

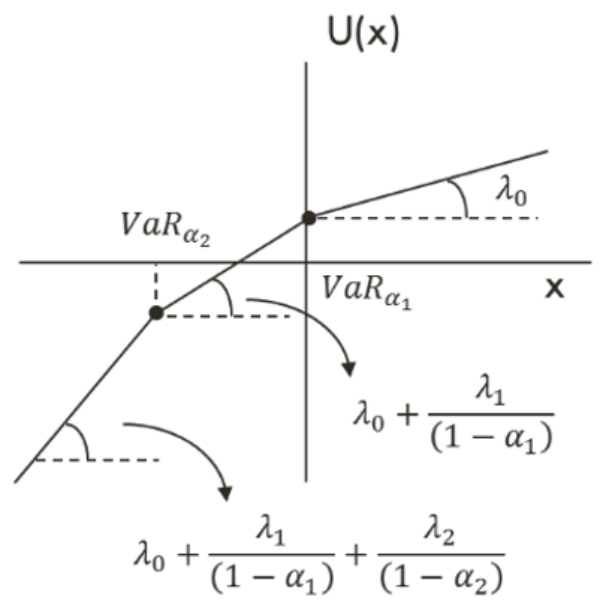

Figura 2.3: Função de utilidade subjacente à medida ECP_G com N=2. Fonte: Luz, 2016.

O equivalente certo da função ECP_G é obtido a partir da aplicação da 
função inversa da utilidade sobre a expectativa de retorno do cenário aleatório. Por conta da natureza segmentar da função de utilidade subjacente à medida ECP_G o seu equivalente certo é descrito por diferentes equações para cada nível de aversão ao risco. Esses intervalos e o cálculo do equivalente certo estão descritas no sistema de equações 2-5 que é apresentado a seguir.

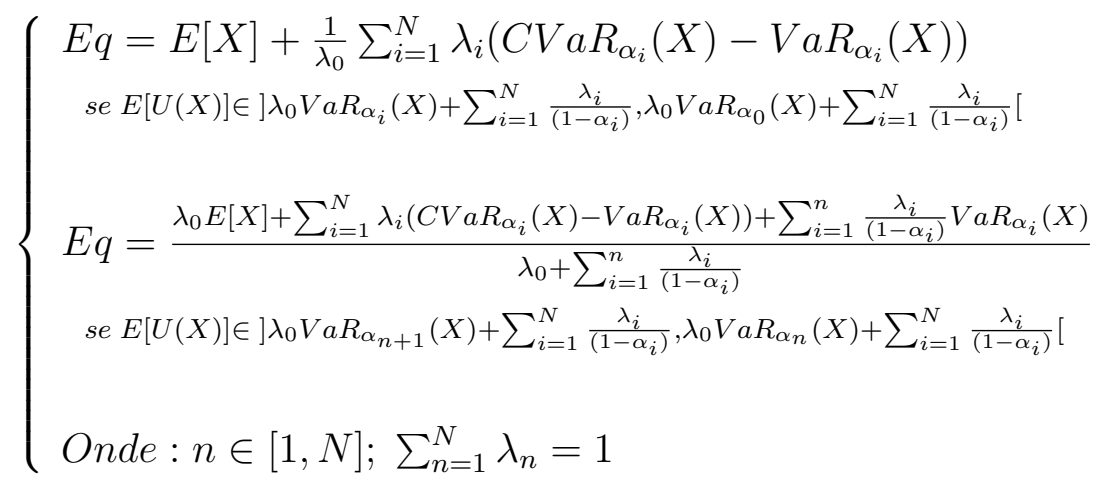

Todos os artigos apresentados neste capítulo formam a estrutura sobre a qual o modelo deste trabalho é concebido. Os conceitos aqui listados serão revisitados no capítulo de metodologia, ou referenciados nos demais. 


\section{3}

\section{Metodologia}

O objetivo deste trabalho é obter um modelo que ofereça um preço de eletricidade a ser usado como referência em um contrato por diferenças para uma transação representativa entre os agentes do mercado de futuros de energia elétrica, de modo que ambos os agentes estejam em equilíbrio dados seus níveis de aversão ao risco.

O modelo construído parte da premissa de que os agentes que formam os preços futuros nos mercados tecem suas expectativas com base em suas características próprias de aversão ao risco, e também em função dos dados disponíveis. O preço de mercado é o agregado dos preços formados por cada transação para um determinado período. Neste sentido, um par de agentes representativos, cujas preferências sejam uma combinação proporcional das preferências de cada agente no mercado, poderia servir como aproximação teórica para a obtenção deste preço médio de equilíbrio.

A fonte de dados mais importante para a determinação do preço futuro é o preço spot esperado. No Brasil o preço da energia elétrica no mercado de curto prazo é determinado pelo modelo de despacho central, que utiliza séries de hidrologia e as limitações da rede de transmissão de energia elétrica, bem como as capacidades de oferta de cada gerador no tempo, para minimizar o custo marginal de operação. Este custo é utilizado como base para o cálculo do preço de liquidação de diferenças (PLD), o preço spot da energia elétrica no mercado de curto prazo.

O modelo utilizará como dado de entrada as séries de PLD e a função ECP_G para estimar a aversão ao risco de cada agente representativo. Outras fontes de dados, experiência prévia ou acontecimentos relevantes que não tenham sido incorporados na otimização do despacho centralizado serão portanto ignorados no modelo e contribuirão para o erro na estimativa final.

\section{1}

\section{Contratos por Diferença}

Contratos por Diferença (CfD) são instrumentos financeiros na forma de um contrato entre duas ou mais partes interessadas em lastrear um valor para um determinado ativo, quer seja com o objetivo de especular em torno da variação de seu valor futuro ou de formar uma garantia contra estas oscilações. Para que um CfD seja possível é necessário que no mínimo duas partes com visões ou necessidades opostas estejam dispostas a concordar com um único 
preço de referência para este ativo em uma data (ou período de entrega) no futuro (Brown et al., 2010).

O CfD possui diversas vantagens que o tornam um instrumento de uso comum em diversos mercados, em especial no mercado de valores mobiliários e commodities. Uma de suas vantagens é ser de baixa complexidade no cálculo das perdas e ganhos, bastando subtrair o preço observado no futuro do preço de referência contratado para calcular o ganho ou perda de cada lado - daí advém o seu nome. Outra vantagem observada neste derivativo é a reduzida necessidade de garantias, uma vez que o contrato não pressupõe a entrega de um ativo físico, e sim trata de uma diferença monetária de preços.

Por isso é possível utilizar este derivativo para realizar operações de grande volume financeiro apenas com pequena margem de garantia, que cubra a oscilações esperadas do preço para aquele período. Por outro lado, o contrato por diferenças quando executado diretamente entre os agentes sem a intermediação de uma bolsa, como é comumente realizado, apresenta risco de contraparte, e os agentes podem solicitar medidas adicionais de proteção como custódia terceirizada dos valores em risco ou contas de garantia. Por esta razão estes instrumentos são utilizados principalmente por agentes que possuem relação de confiança prévia, em transações particulares.

A receita dos participantes do CfD dependem da premissa que cada lado assumiu. O lado comprador se beneficiará caso o preço observado no futuro seja maior do que o preço de referência do contrato. Na parte oposta o lado vendedor se beneficiará caso o preço observado no futuro seja menor do que o preço de referência do contrato. O sistema de equações 3-1 descreve a receita do comprador e do vendedor, assumindo um cenário sem custos de transação ou outros de qualquer espécie.

$$
\left\{\begin{array}{l}
\pi_{C_{t}}=\left(p_{S_{t}}-p_{K}\right) \times Q \\
\pi_{V_{t}}=\left(p_{K}-p_{S_{t}}\right) \times Q
\end{array}\right.
$$

Onde $\pi_{C_{t}}$ e $\pi_{V_{t}}$ são, respectivamente, a receita do comprador e do vendedor no tempo t, $p_{K}$ é o preço de referência firmado no contrato entre as partes, $p_{S_{t}}$ é o preço spot observado no tempo t e $Q$ é a quantidade de ativo subjacente a qual o contrato se refere.

\subsection{1}

\section{Contratos por Diferença no Setor Elétrico}

Os contratos por diferença são amplamente utilizados no setor elétrico e serviram para facilitar a migração para o uso de fontes reno- 
váveis no Reino Unido (Onifade, 2016). Novas publicações buscam utilizar os CfD em novas propostas no contexto das energias renováveis (Welisch \& Poudineh, 2020). Diversos trabalhos utilizam o CfD como instrumento para estudar o setor elétrico, em particular no mercado nórdico (Kristiansen, 2004, Marckhoff \& Wimschulte, 2009, Ferkingstad et al., 2014).

Os contratos utilizados no fornecimento ou consumo de eletricidade costumam abranger uma determinada quantidade durante um período, ao invés terem uma única data de entrega. Assim o contrato por diferenças pode ser enxergado como uma combinação aritmética de diferentes contratos com prazos menores de entrega, até atingir o nível mínimo discricionário.

No mercado brasileiro o uso de CfD é comum entre grandes geradores e distribuidores de eletricidade. O contrato é geralmente utilizado para hedge ou com o intuito de assegurar um preço futuro e evitar a exposição à cenários adversos de preço, porém pode ser feito também com objetivo especulativo. Os contratos podem ser feitos sem data de expiração, sendo interrompidos por solicitação de uma das partes.

\section{2 Demonstração de que o modelo abrange todos os participantes do mercado}

Demonstrarei que o contrato por diferenças é suficiente para modelar a participação de todos os agentes interessados em ter uma posição no mercado futuro de eletricidade. Não é necessário esclarecer que o contrato por diferenças é uma ferramenta adequada para o agente especulador que deseja ter uma exposição ao preço futuro de eletricidade pois este é um uso comum desta ferramenta e sua utilização no mercado de futuro de eletricidade foi apresentada na seção anterior (Brown et al., 2010).

Nesta seção é demonstrado que o contrato por diferenças também é adequado para representar a posição de agentes que já possuem exposição ao preço futuro de eletricidade e desejam alterar o grau desta exposição, utilizando a ferramenta financeira como um seguro, ou instrumento de alavancagem. Todos os participantes do mercado que tem parte de sua receita atrelada ao preço de curto prazo podem utilizar instrumentos de mitigação de risco, e estes instrumentos podem ser representados por uma série de contratos por diferenças.

Tome-se como exemplo o cenário em que um gerador de eletricidade tem a maior parte de suas vendas futuras atrelada a contratos de longo prazo mas uma pequena porção exposta ao PLD. Neste caso a receita deste gerador pode ser expressa pela seguinte equação: 


$$
R_{G t}=G_{L P} \times p_{L P}+\left(G-G_{L P}\right) \times p_{S t}
$$

Onde $R_{G t}$ é a receita do gerador no tempo t, G é a geração total neste período, $G_{L P}$ é a geração que está comprometida com contratos de longo prazo, $p_{L P}$ é o preço médio determinado nos contratos de longo prazo e $p_{S t}$ é o preço spot de energia no período t.

Caso este gerador decida proteger-se do risco de curto prazo pode fazêlo adquirindo um contrato por diferenças para uma determinada quantidade que está descoberta. A nova equação de receita do gerador irá incorporar este elemento de segurança.

$$
R_{G t}=G_{L P} \times p_{L P}+Q \times p_{K}+\left(G-G_{L P}-Q\right) \times p_{S t}
$$

Obtendo a diferença entre as equações 3-2 e 3-3 acima é obtido o resultado que demonstra que a proteção obtida pelo gerador pode adequadamente ser representada pela equação do contrato por diferenças, presente no sistema de equações 3-1.

$$
\Delta R_{G}=Q \times p_{C}-Q \times p_{S t}=\left(p_{K}-p_{S t}\right) \times Q
$$

Um resultado análogo pode ser obtido para o caso em que o comprador de energia tem parte de sua despesa atrelada ao preço de curto prazo. Neste caso, é a diferença entre as equações de despesa que irão ser similares à equação do contrato por diferenças, como pode ser visto nas equações 3-5 abaixo.

$$
\begin{array}{r}
D_{C t}=-E_{L P} \times p_{L P}-\left(E-E_{L P}\right) \times p_{S t} \\
D_{C t}=-E_{L P} \times p_{L P}-Q \times p_{K}-\left(E-E_{L P}-Q\right) \times p_{S t} \\
\Delta D_{C}=-Q \times p_{K}+Q \times p_{S t}=\left(p_{S t}-p_{K}\right) \times Q
\end{array}
$$

Logo, como queria se demonstrar, todos os participantes podem utilizar as equações do contrato por diferenças para quantificar sua exposição ao preço futuro de eletricidade, inclusive aqueles que não fizeram uso efetivo deste derivativo. Isso torna o modelo que utiliza o contrato por diferenças como aproximação do posicionamento de todos os agentes do mercado uma opção de modelagem verossímil. 


\section{3}

\section{Dados utilizados}

Os dados utilizados neste trabalho consistem de séries de estimativas de preço spot futuro de energia elétrica provenientes do despacho centralizado do ONS e também curvas forward divulgadas por especialistas da DCide Energia. As séries foram obtidas na última semana de cada mês, e foram coletados em dois momentos distintos: janeiro de 2019 e agosto de 2019.

Os dados de PLD contém duas mil estimativas de preços spot futuro, com valores específicos para cada mês em análise. As séries obtidas em janeiro de 2019 contém estimativas mensais para o preço spot futuro no ano de 2020 e também para o ano de 2021. As obtidas em agosto de 2019 contém as estimativas mensais para o ano de 2020, apenas.

A tabela 3.1 lista a natureza, período de referência, data de obtenção e fonte de cada dado utilizado no modelo.

Tabela 3.1: Dados de entrada do modelo, por tipo, período e fonte.

\begin{tabular}{|l|l|l|l|l|}
\hline Tipo do dado & Período & Obtenção & Fonte & Utilização \\
\hline Preço spot futuro & Ano de 2020 & jan/2019 & ONS & Treinamento \\
Preço spot futuro & Ano de 2021 & jan/2019 & ONS & Validação \\
Preço spot futuro & Ano de 2020 & ago/2019 & ONS & Validação \\
Preço forward & Ano de 2020 & jan/2019 & DCide & Treinamento \\
Preço forward & Ano de 2021 & jan/2019 & DCide & Validação \\
Preço forward & Ano de 2020 & ago/2019 & DCide & Validação \\
\hline
\end{tabular}

Os preços forward obtidos com a DCide Energia foram coletados nas mesmas datas que as séries de PLD, de modo que contivessem na análise dos especialistas apenas os dados disponíveis naquele momento, sem informação futura. Em janeiro de 2019 foram coletadas duas estimativas para o preço forward de energia elétrica, uma média anual para 2020 e outra para 2021. Em agosto de 2019 foi obtido um preço forward médio anual para o ano de 2020. Deste modo as expectativas de preço forward estão alinhadas temporalmente com os dados de preço spot futuro.

\section{4}

\section{Desenho do modelo}

O modelo apresentado nesta seção foi composto a partir de um equilíbrio entre dois agentes representativos do mercado de futuros de energia, transacionando lados opostos de um contrato de diferenças para um determinado montante de energia em um período no futuro. A partir das equações apresentadas na seção anterior para o contrato por diferenças foi construído um fluxo 
de caixa descontado para o resultado financeiro desta operação, do ponto de vista de cada agente.

Abaixo estão descritas as equações 3-6 e 3-7 que representam o fluxo de caixa para cada agente representativo, vendedor e comprador do contrato por diferenças para energia elétrica para o período de um ano.

$$
\begin{aligned}
& \pi_{V}=\sum_{i=1}^{12} \frac{Q h_{i} \times\left(p_{K}-p_{S_{i}}\right)}{(1+j)^{i}} \\
& \pi_{C}=\sum_{i=1}^{12} \frac{Q h_{i} \times\left(p_{S_{i}}-p_{K}\right)}{(1+j)^{i}}
\end{aligned}
$$

Onde $\pi_{V}$ e $\pi_{C}$ são a remuneração do contrato por diferenças para o vendedor do contrato e para o comprador, respectivamente; $i$ representa os meses do contrato; $Q$ é a quantidade de energia a ser transacionada, $h_{i}$ a quantidade de horas em cada mês $i ; p_{K}$ o preço estabelecido nos contratos por diferença; $p_{S_{i}}$ o preço spot futuro para o mês $i$; e $j$ a taxa de desconto do capital.

O preço spot futuro utilizado no fluxo de caixa é o dado de PLD obtido do modelo Newave-Decomp do ONS. O preço do contrato por diferenças não está definido e será utilizado como uma aproximação do preço forward no mercado para o período em análise, a partir do equilíbrio na relação entre os agentes. O preço do contrato tem o mesmo valor para o comprador e para o vendedor.

Note-se que os termos comprador e vendedor são distintos quando utilizados para o vendedor de energia elétrica e o vendedor do contrato por diferenças, por exemplo. Neste trabalho os termos comprador e vendedor, quando usados isoladamente, sempre se referirão à operação com o contrato por diferenças.

No caso geral, em uma negociação de um CfD, a definição do preço do contrato pode ser feita através de diferentes métodos. Em geral o preço é determinado em uma negociação particular entre os agentes contemplados no contrato por diferenças, de acordo com suas percepções e informações a respeito dos preços futuros. Neste trabalho assumimos que toda informação sobre o preço futuro está contida nas séries de preço divulgadas pelo ONS, e os agentes representativos determinam suas expectativas baseando-se nestes dados. O preço de equilíbrio é considerado o preço em que ambos os agentes representativos concordam com o valor do contrato de acordo com suas preferências. Na próxima seção serão descritos os métodos de equilíbrio que são utilizados neste trabalho. 


\subsection{1}

\section{Método neutro ao risco}

Utilizando uma planilha de Excel foi feito um fluxo de caixa descontado para uma transação de um contrato por diferenças entre dois agentes representativos dos integrantes do mercado interessados em uma posição defensiva (ou especulativa) para compra ou venda de energia elétrica para o período em análise. A taxa de remuneração de capital utilizada no fluxo de caixa é de $10 \%$ ao ano. A quantidade de energia transacionada foi arbitrada em 100 MWh.

A primeira simulação realizada parte da premissa que os agentes representativos são neutros ao risco. Deste modo, o resultado, embora trivial, demonstra algumas características interessantes para a utilização do modelo. Sendo neutros ao risco, o equilíbrio será diretamente obtido através da equalização do resultado financeiro. Como o contrato por diferenças é uma ferramenta em que o resultado financeiro é necessariamente positivo para uma parte somente quando é negativo para a outra parte, o único cenário em que ambos obtém o mesmo resultado é no caso em que o preço de contrato é idêntico a média do preço spot esperado para o período.

Este resultado pode ser observado intuitivamente, como exposto acima, e também através de método analítico. A partir das equações 3-6 e 3-7, estabelecemos que o equilíbrio pode ser obtido através da minimização da diferença ao quadrado dos resultados financeiros de ambos os agentes representativos. Para simplificar a análise, estabeleceremos o período do contrato por diferenças para um único ano, sem discretizar os valores mensalmente. Assim definimos uma função objetivo como se segue:

$$
\begin{array}{r}
O b j=\operatorname{Min}\left\{\left(E\left[\pi_{V}\right]-E\left[\pi_{C}\right]\right)^{2}\right\} \\
O b j=\operatorname{Min}\left\{\left[\frac{Q h \times\left(2 p_{K}-2 E\left[p_{S}\right]\right)}{1+j_{a}}\right]^{2}\right\}
\end{array}
$$

Obtendo a derivada da função objetivo para a variável de equilíbrio podemos redefinir a equação 3-8 e obter o resultado que confirma a intuição anterior.

$$
\begin{array}{r}
\frac{d O b j}{d p_{K}}=\frac{4 Q h}{1+j_{a}} \times\left(2 p_{K}-2 E\left[p_{S}\right]\right)=0 \\
p_{K}=E\left[p_{S}\right]
\end{array}
$$

É interessante observar que, enquanto a taxa de desconto intertemporal, a quantidade de energia transacionada e o número de horas por mês tiverem 
o mesmo valor para ambos os agentes, estas variáveis não são relevantes para a determinação do preço de equilíbrio em um período único.

No caso em que a remuneração dos agentes é calculada mês a mês, aplicando-se o número de horas discretamente e a taxa de juros mensal, o preço de equilíbrio será uma média aritmética ponderada pelo número de horas e a taxa de juros.

$$
p_{K}=\frac{\sum_{i=1}^{n} p_{S_{i}} \times h_{i} \times(1+j)^{(n-i)}}{n \times \sum_{i=1}^{n} h_{i} \times(1+j)^{(n-i)}}
$$

Mesmo neste caso, se a taxa de juros for muito baixa, e se considerarmos que a diferença entre o número de horas em cada mês e a média de horas por mês é negligível, veremos que a aproximação obtida na equação 3-9 é bastante semelhante ao resultado obtido pela equação 3-10.

\subsection{2}

\section{Método avesso ao risco}

Caso os agentes fossem neutros ao risco o preço spot esperado seria uma boa aproximação para o preço forward de eletricidade, conforme foi visto na seção anterior. No entanto o caso neutro ao risco não costuma explicar o comportamento de agentes em situações normais de transação, pois ainda haveria uma diferença entre o preço médio ponderado e o preço forward, diferença esta que pode ser explicada pela aversão ao risco dos agentes financeiros. Os agentes podem apresentar uma tendência a valorizar mais uma perda do que um ganho e neste caso a curva de reação, ou de preferência, passa a ser determinada por índices de aversão ao risco de perda.

Nesta subseção será utilizada a função ECP_G para determinar o comportamento de aversão ao risco dos agentes representativos. A função objetivo da otimização é definida pela minimização da diferença quadrática dos equivalentes certos para o vendedor e o comprador do contrato por diferenças, conforme definido pela equação 2-5.

$$
O b j=\operatorname{Min}\left\{\left(E q_{V}-E q_{C}\right)^{2}\right\}
$$

O uso do equivalente certo tem a vantagem de ter o seu resultado expresso em valores financeiros, e estes podem, portanto, ser comparados entre agentes com diferentes curvas de aversão ao risco, sem a necessidade de uma medida unificadora de utilidade. 
Neste trabalho foram desenvolvidos dois algoritmos distintos para incorporar a aversão ao risco dos agentes. A razão pela qual os dois algoritmos serão utilizados é que enquanto o primeiro utiliza um fluxo de caixa descontado e o segundo é uma análise de equilíbrio discreta, ambos apresentam resultados semelhantes. O segundo algoritmo tem a vantagem de ter uma estrutura analítica transparente e apresentar resultados mensais.

\subsubsection{1}

\section{Algoritmo 1: equilíbrio pelo resultado anual do fluxo de caixa descontado}

O primeiro método utiliza o mesmo fluxo de caixa feito para o caso neutro ao risco, alterando a função objetivo da otimização para utilizar o equivalente certo dos agentes segundo a função ECP_G. A equação do equivalente certo do ECP_G para o caso em que há dois níveis de aversão ao risco apresenta 4 incógnitas para cada agente, representando um total de oito variáveis que precisam ser otimizadas. Estas variáveis são os dois níveis de aversão ao risco de cada termo de CVaR $\left(\alpha_{1}\right.$ e $\left.\alpha_{2}\right)$ e os dois pesos para cada termo $\left(\lambda_{1}\right.$ e $\left.\lambda_{2}\right)$.

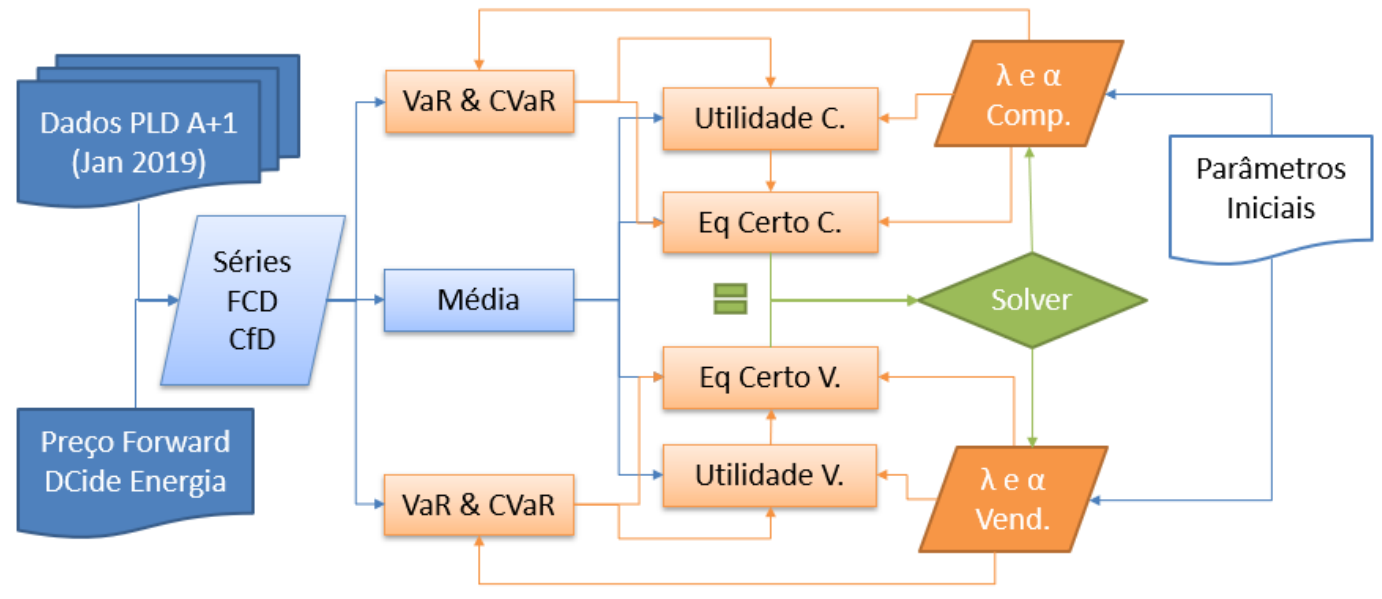

Figura 3.1: Fluxograma de treinamento do algoritmo 1. Fonte: Elaboração Própria.

Nessa seção estão expostas, na forma de um algoritmo, as etapas de cálculo para a obtenção do preço de equilíbrio. O primeiro passo é estabelecer os valores ótimos destes parâmetros de aversão ao risco. Os dados de PLD coletados em uma planilha de Excel foram estruturados utilizando as equações de cálculo apresentadas na seção anterior para a realização de uma otimização utilizando a ferramenta Solver, que permite aplicar limites para cada uma das variáveis otimizadas. $\mathrm{O}$ preço de contrato $p_{K}$ foi fixado no valor da previsão feita pela DCide para o preço forward médio no ano de 2020, obtida na última semana do mês de janeiro de 2019. Os dados de PLD de janeiro obtidos da 
CCEE servem como fonte de treinamento do modelo, oferecendo diferentes séries para a otimização dos parâmetros de aversão ao risco.

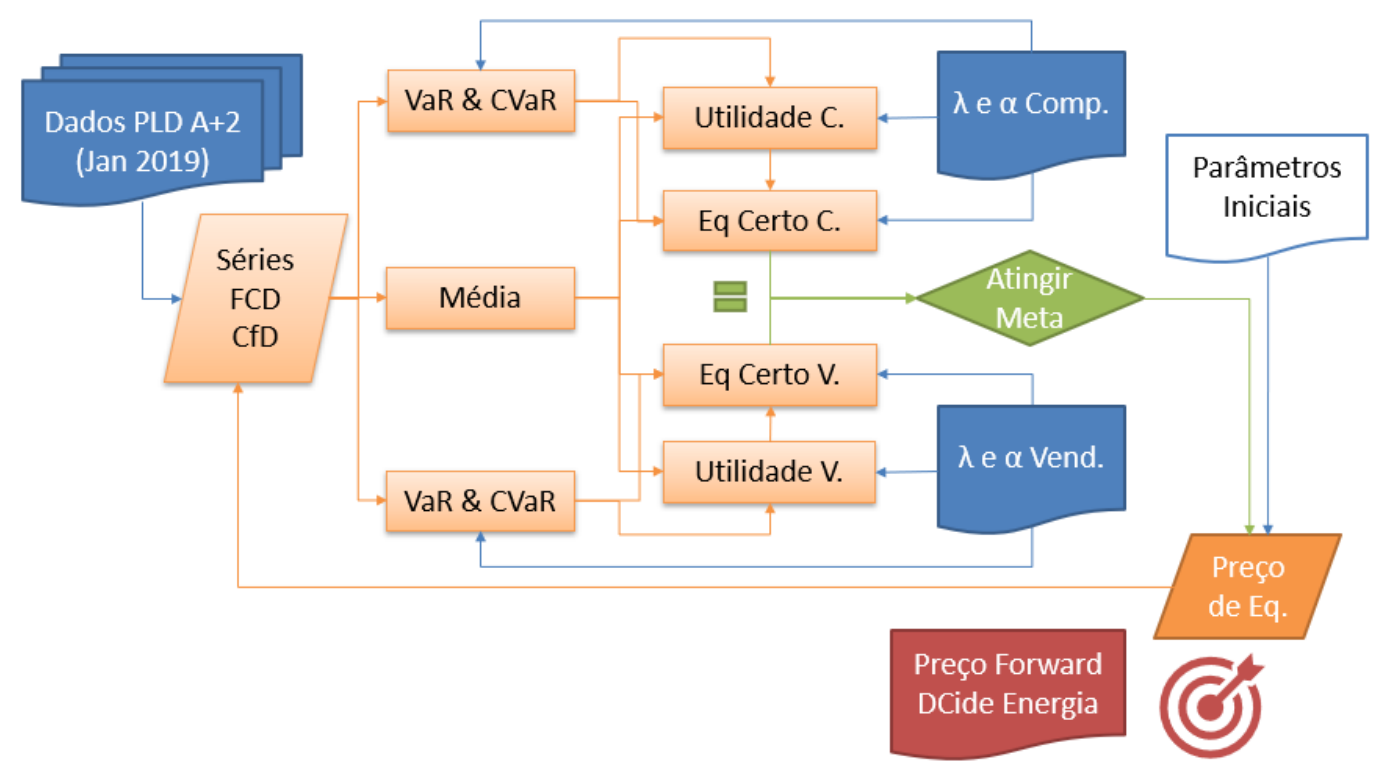

Figura 3.2: Fluxograma de validação do algoritmo 1. Fonte: Elaboração Própria.

A otimização com o Solver foi acionada tendo dois pontos de partida distintos: todas as variáveis com valor mínimo e todas as variáveis com valor máximo. Em ambos os casos o equilíbrio foi encontrado e com uma diferença desprezível entre os resultados. Esta convergência empresta maior confiança aos valor dos parâmetros otimizados .

Para a validação deste modelo outras seções foram criadas na planilha Excel calculando o equilíbrio a partir dos parâmetros otimizados obtidos no passo anterior. As validações feitas neste trabalho utilizaram os dados obtidos em janeiro de 2019 para o ano de 2021 e em agosto de 2019 para o ano de 2020, e os resultados estão apresentados no capítulo seguinte. Nestes casos o preço de equilíbrio é alcançado utilizando a ferramenta Atingir Meta do Excel, buscando o preço de contrato que equaliza o equivalente certo dos agentes representativos. Os preços de equilíbrio obtidos nas rodadas de validação podem ser comparados às estimativas da curva forward obtidas com a DCide Energia para os mesmos períodos.

\subsubsection{2}

\section{Algoritmo 2: preços de equilíbrio definidos a cada mês}

Com o intuito de observar o equilíbrio discretamente, mês a mês, um segundo algoritmo de equilíbrio foi elaborado em outra planilha de Excel. Partindo da equação de otimização simplificada 3-9 obtida no caso neutro 


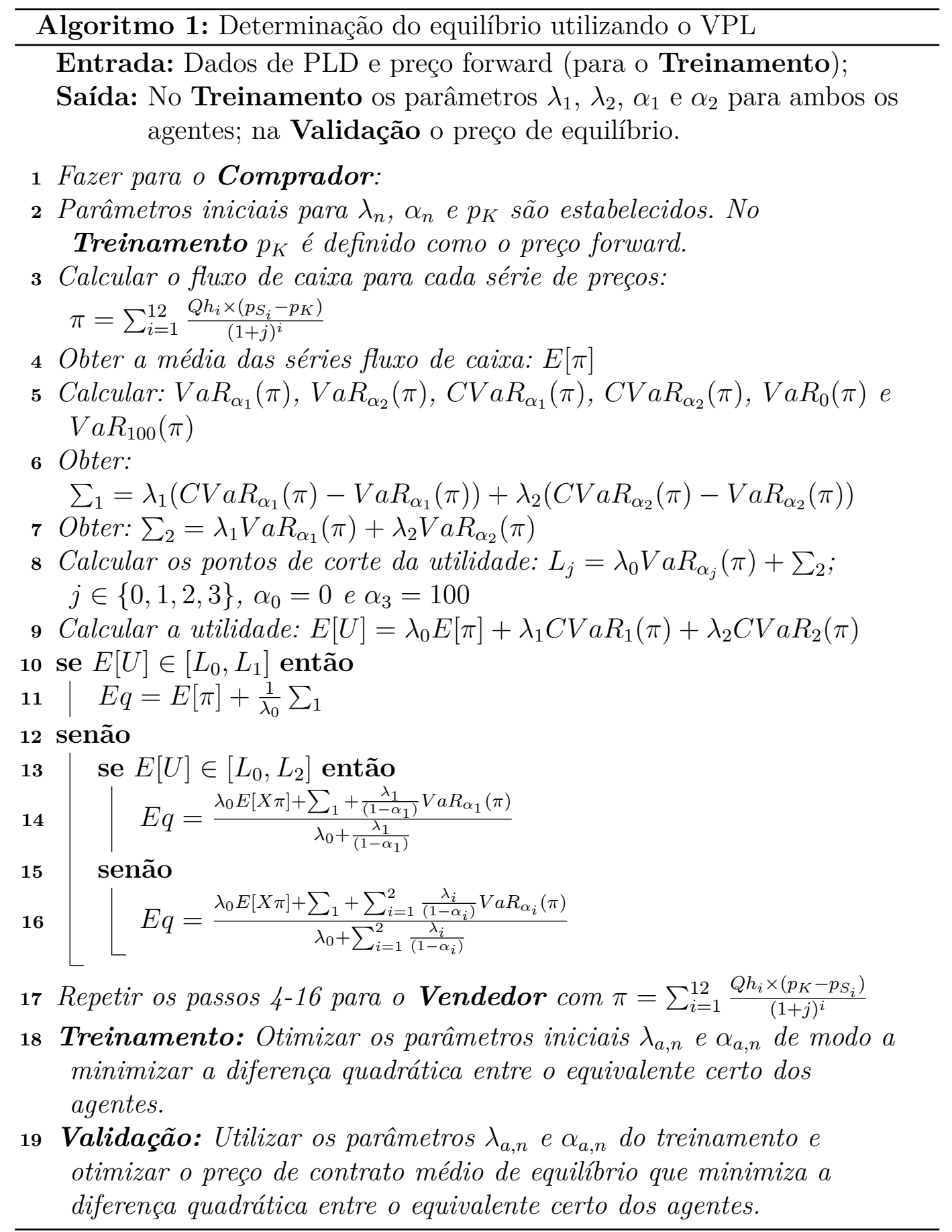


ao risco foi desenvolvida uma solução analítica para o equilíbrio também no caso avesso ao risco.

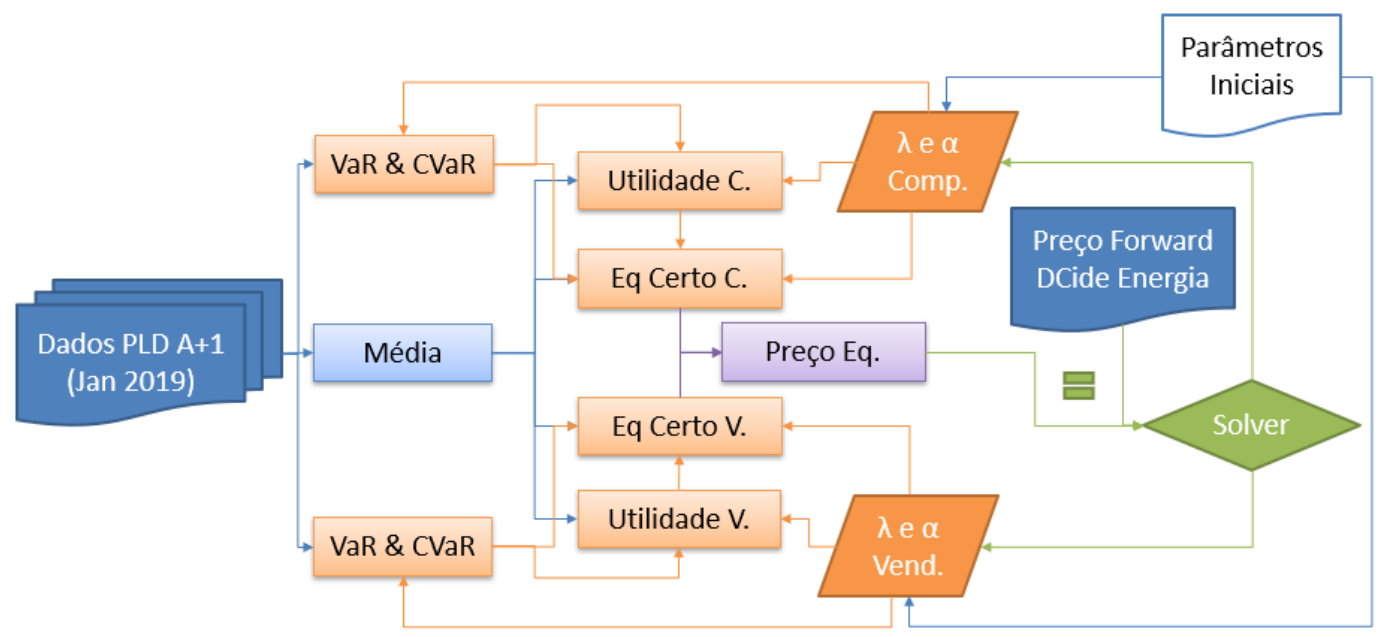

Figura 3.3: Fluxograma de treinamento do algoritmo 2. Fonte: Elaboração Própria.

Em geral os parâmetros da função ECP_G são utilizados para calcular intervalos de nível de risco dentro dos quais aplica-se uma função utilidade linear. Embora globalmente a curva de aversão ao risco seja côncava, para cada trecho em análise no equilíbrio é utilizada uma função linear. No caso em que os parâmetros do modelo já foram otimizados, haverá uma solução única para o equilíbrio entre os agentes.

Para encontrar a equação que calcula o preço de equilíbrio define-se a função objetivo como a minimização da diferença do equivalente certo dos agentes representativos. Toma-se como ponto de partida a equação geral para o equivalente certo, obtida à partir da equação 2-5. Esta equação pode ser transformada nas demais equações específicas para cada intervalo atribuindose um valor nulo para os pesos $\lambda$ que se encontram fora do intervalo, como será explicado no algoritmo 2 apresentado à frente.

$$
E q_{A}=\frac{\lambda_{0} E\left[\pi_{A}\right]+\sum_{n=1}^{2} \lambda_{n}\left(C V a R_{\alpha_{n}}\left(\pi_{A}\right)-V a R_{\alpha_{n}}\left(\pi_{A}\right)\right)+\sum_{n=1}^{2} \frac{\lambda_{n}}{1-\alpha_{n}} V a R_{\alpha_{n}}\left(\pi_{A}\right)}{\lambda_{0}+\frac{\lambda_{1}}{1-\alpha_{1}}+\frac{\lambda_{2}}{1-\alpha_{2}}}
$$

Como o intuito da otimização é determinar o preço de contrato que oferece o equilíbrio entre o equivalente certo dos agentes, a equação 3-12 será reescrita para cada agente substituindo o retorno financeiro pela equação do contrato por diferenças, obtida a partir das equações 3-6 e 3-7. Como foi observado no caso neutro ao risco, as variáveis $Q, h$ e $j$, sendo as mesmas para ambos os agentes e utilizadas em um único período de tempo, não influenciam 
no preço de equilíbrio. Para simplificar, portanto, serão considerados valores neutros para as variáveis exógenas ao equilíbrio, ou seja, $Q=1, h=1$ e $j=0$.

$$
\begin{aligned}
& \pi_{C t}=p_{S t}-p_{K} \\
& \pi_{V t}=p_{K}-p_{S t}
\end{aligned}
$$

Substituindo a primeira equação 3-13 em 3-12 para o comprador obtém-se o seguinte resultado.

$$
\begin{array}{r}
E q_{C t}=\frac{\lambda_{0}\left(E\left[p_{S t}\right]-p_{K}\right)+\sum_{C t}+\sum_{n=1}^{2} \frac{\lambda_{n}}{1-\alpha_{n}}\left(\operatorname{VaR} R_{\alpha_{n}}\left(p_{S t}\right)-p_{K}\right)}{\lambda_{0}+\frac{\lambda_{1}}{1-\alpha_{1}}+\frac{\lambda_{2}}{1-\alpha_{2}}} \\
E q_{C t}=\frac{-p_{K} \times\left(\lambda_{0}+\frac{\lambda_{1}}{1-\alpha_{1}}+\frac{\lambda_{2}}{1-\alpha_{2}}\right)}{\lambda_{0}+\frac{\lambda_{1}}{1-\alpha_{1}}+\frac{\lambda_{2}}{1-\alpha_{2}}}+\frac{\lambda_{0} E\left[p_{S t}\right]+\sum_{C t}+\sum_{n=1}^{2} \frac{\lambda_{n} V a R_{\alpha_{n}}\left(p_{S t}\right)}{1-\alpha_{n}}}{\lambda_{0}+\frac{\lambda_{1}}{1-\alpha_{1}}+\frac{\lambda_{2}}{1-\alpha_{2}}} \\
E q_{C t}=-p_{K}+\frac{\lambda_{0} E\left[p_{S t}\right]+\sum_{C t}+\sum_{n=1}^{2} \frac{\lambda_{n} V a R_{\alpha_{n}}\left(p_{S t}\right)}{1-\alpha_{n}}}{\lambda_{0}+\frac{\lambda_{1}}{1-\alpha_{1}}+\frac{\lambda_{2}}{1-\alpha_{2}}}
\end{array}
$$

Onde :

$$
\begin{array}{r}
\sum_{C t}=\sum_{n=1}^{2} \lambda_{n}\left(C V a R_{\alpha_{n}}\left(p_{S t}\right)-p_{K}-V_{a} R_{\alpha_{n}}\left(p_{S t}\right)+p_{K}\right) \\
\sum_{C t}=\sum_{n=1}^{2} \lambda_{n}\left(C V a R_{\alpha_{n}}\left(p_{S t}\right)-\operatorname{VaR}_{\alpha_{n}}\left(p_{S t}\right)\right)
\end{array}
$$

De modo análogo poderemos encontrar a equação do equivalente certo definida em função do preço de contrato para o vendedor através das seguintes equações.

$$
\begin{array}{r}
E q_{V t}=p_{K}+\frac{\lambda_{0} E\left[-p_{S t}\right]+\sum_{V t}+\sum_{n=1}^{2} \frac{\lambda_{n} V a R_{\alpha_{n}}\left(-p_{S t}\right)}{1-\alpha_{n}}}{\lambda_{0}+\frac{\lambda_{1}}{1-\alpha_{1}}+\frac{\lambda_{2}}{1-\alpha_{2}}} r \\
\quad \text { Onde }: \\
\sum_{V t}=\sum_{n=1}^{2} \lambda_{n}\left(C V a R_{\alpha_{n}}\left(-p_{S t}\right)-V a R_{\alpha_{n}}\left(-p_{S t}\right)\right)
\end{array}
$$

Observa-se que as equações 3-14 e 3-15 podem ser reescritas como uma combinação aritmética do preço de contrato $p_{K}$ e uma fórmula de equivalente certo que utiliza como variável apenas o preço spot esperado no período t, $p_{S t}$. Assim podemos definir uma notação auxiliar para estes segundos termos 
denominados aqui $E q_{p_{C t}}$ e $E q_{p_{V t}}$.

$$
\begin{gathered}
E q_{p_{C t}}=\frac{\lambda_{0} E\left[p_{S t}\right]+\sum_{n=1}^{2} \lambda_{n}\left(C V a R_{\alpha_{n}}\left(p_{S t}\right)-V a R_{\alpha_{n}}\left(p_{S t}\right)\right)+\sum_{n=1}^{2} \frac{\lambda_{n} V a R_{\alpha_{n}}\left(p_{S t}\right)}{1-\alpha_{n}}}{\lambda_{0}+\frac{\lambda_{1}}{1-\alpha_{1}}+\frac{\lambda_{2}}{1-\alpha_{2}}} \\
E q_{p_{V t}}=\frac{\lambda_{0} E\left[-p_{S t}\right]+\sum_{n=1}^{2} \lambda_{n}\left(C V a R_{\alpha_{n}}\left(-p_{S t}\right)-V a R_{\alpha_{n}}\left(-p_{S t}\right)\right)+\sum_{n=1}^{2} \frac{\lambda_{n} V a R_{\alpha_{n}}\left(-p_{S t}\right)}{1-\alpha_{n}}}{\lambda_{0}+\frac{\lambda_{1}}{1-\alpha_{1}}+\frac{\lambda_{2}}{1-\alpha_{2}}}
\end{gathered}
$$

Uma vez redefinidos os termos da equação de equivalente certo, o passo seguinte é substituir as equações 3-16 na equação de objetivo de otimização 311 com o intuito de obter uma equação única em função do preço de equilíbrio.

$$
\begin{array}{r}
O b j=\operatorname{Min}\left\{\left[Q h \times\left(2 p_{K}+E q_{p_{V t}}-E q_{p_{C t}}\right)^{2}\right]\right\} \\
\frac{d O b j}{d p_{K}}=4 Q h \times\left(2 p_{K}+E q_{p_{V t}}-E q_{p_{C t}}\right)=0 \\
p_{K}=\frac{\left(E q_{p_{C t}}-E q_{p_{V t}}\right)}{2}
\end{array}
$$

Observe-se que como o resultado de $E q_{p_{V t}}$ é necessariamente negativo, o preço de equilíbrio é portanto definido como uma média aritmética do equivalente certo em função do preço spot esperado para os agentes representativos.

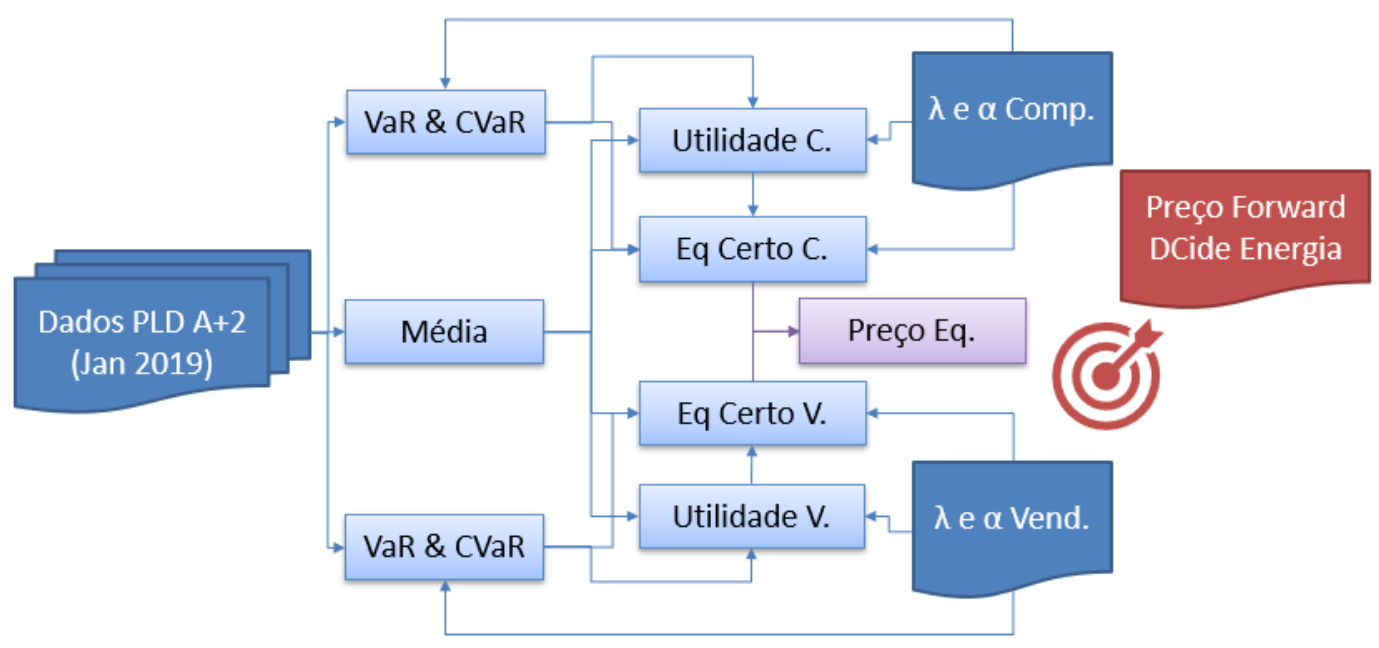

Figura 3.4: Fluxograma de validação do algoritmo 2. Fonte: Elaboração Própria.

Utilizando a equação 3-17 um algoritmo foi programado em uma planilha Excel de modo a obter os parâmetros de aversão ao risco para a função ECP_G 
que atinjam o preço de equilíbrio idêntico ao previsto pelos especialistas, na etapa de treinamento do modelo. Os passos deste algoritmo estão descritos a seguir.

Os resultados do treinamento e rodadas de validação do segundo algoritmo também estão expostos em uma seção própria no capítulo seguinte. 


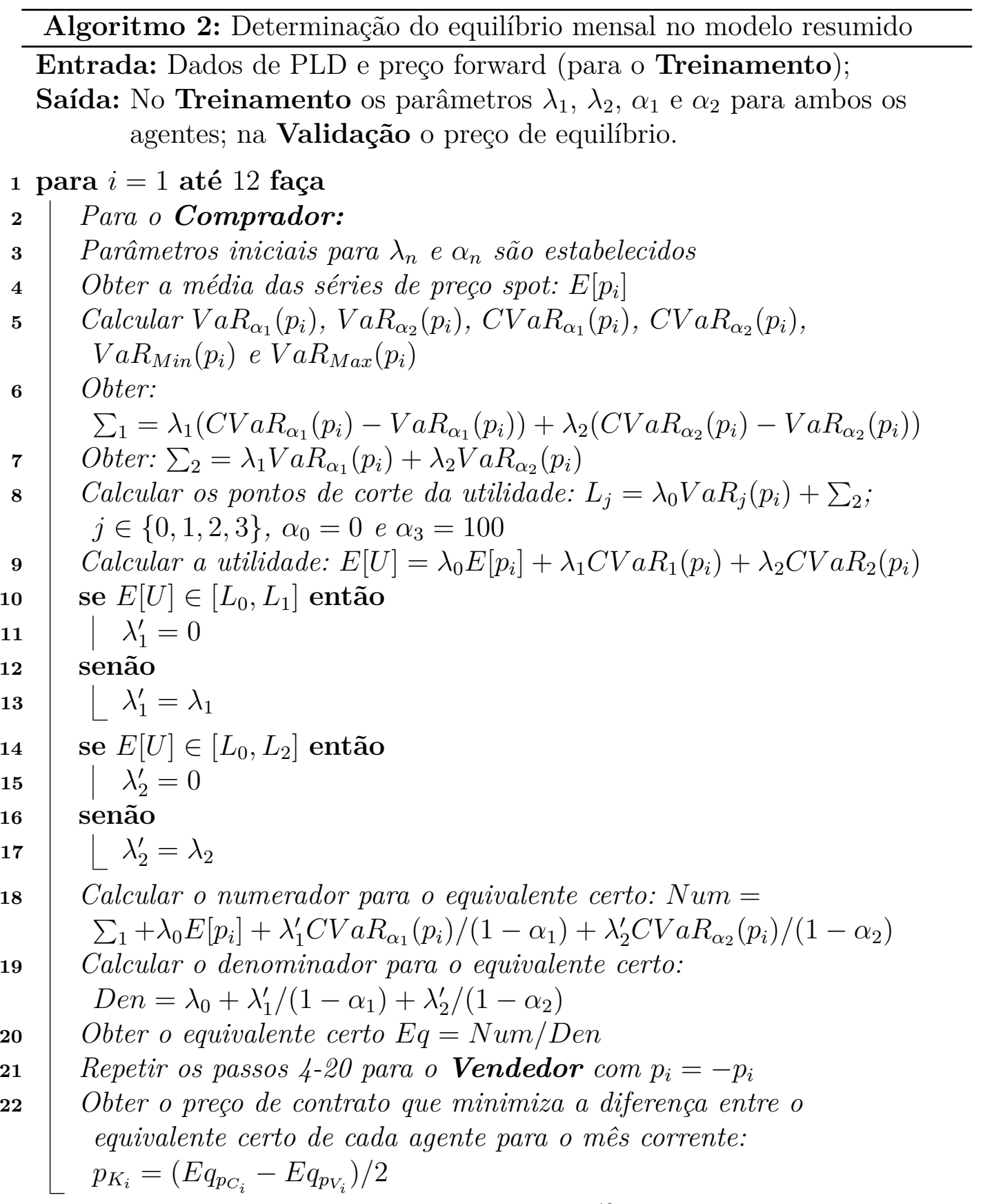

23 Obter o preço médio de equilíbrio: $E\left[p_{K}\right]=\frac{\sum_{i=1}^{12} p_{K_{i}} \times h_{i} \times(1+j)^{(n-i)}}{12 \times \sum_{i=1}^{12} h_{i} \times(1+j)^{(n-i)}}$

24 Treinamento: Otimizar os parâmetros iniciais $\lambda_{a, n}$ e $\alpha_{a, n}$ de modo a minimizar a diferença quadrática entre o preço de contrato médio obtido e o determinado por especialistas.

25 Validação: Utilizar os parâmetros $\lambda_{a, n}$ e $\alpha_{a, n}$ otimizados para calcular diretamente o preço de contrato médio de equilíbrio. 


\section{Resultados e discussão}

\section{1}

\section{Análise dos dados de preço spot futuro}

Os dados de CMO obtidos do modelo de despacho centralizado NewaveDecomp foram tratados para se alinhar com a expectativa de preço spot futuro. Para este trabalho foi suficiente apenas limitar os valores mínimo e máximo destes preços segundo os valores legais vigentes no período, nominalmente 42,35 $\mathrm{R} \$ / \mathrm{MWh}$ para o piso e 513,89 R\$/MWh para o teto.

Abaixo estão os gráficos do tipo box and whiskers elaborados no Excel para os dados de entrada do modelo, de modo a facilitar a visualização da distribuição do preço em torno de seus quartis e de sua média. Nas figuras abaixo os dados que ficam entre o terceiro e o primeiro quartil estão representados dentro de um retângulo e a mediana é representada por uma linha horizontal dentro do retângulo, ou coincidente com um de seus limites. Acima ou abaixo estão os representados pelo fio do bigode os dados que se encontram entre o limite do retângulo e 1,5 vezes a amplitude interquartil, ou os dados outlier representados por pequenos círculos. A média também é representada, com o símbolo $\times$.

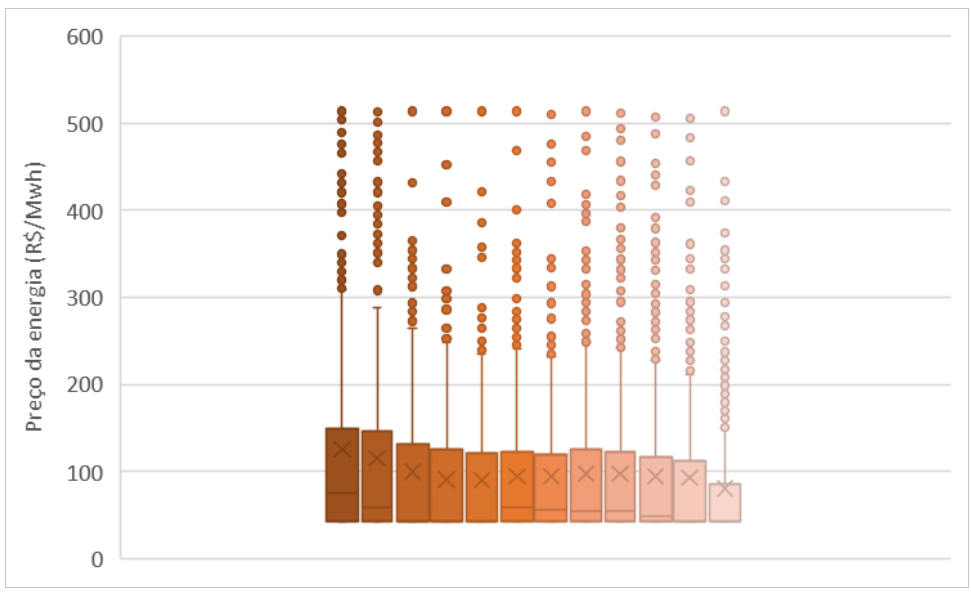

Figura 4.1: Distribuição de preços spot esperados por mês para o ano de 2020 - Dados de janeiro/2019. Fonte: Elaboração Própria.

É possível observar para todos os períodos um forte desvio para a esquerda, com maior concentração em torno do valor mínimo. Este padrão é esperado para o PLD, que deverá ser baixo em situações normais, e alto apenas em situações de exceção. Este padrão de assimetria deve conduzir a diferentes 


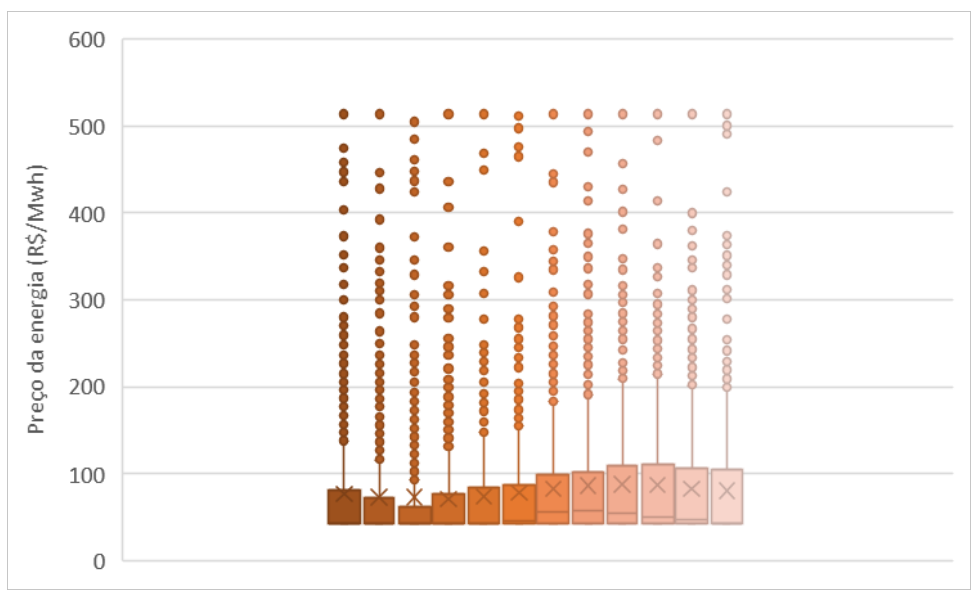

Figura 4.2: Distribuição de preços spot esperados por mês para o ano de 2021 - Dados de janeiro/2019. Fonte: Elaboração Própria.

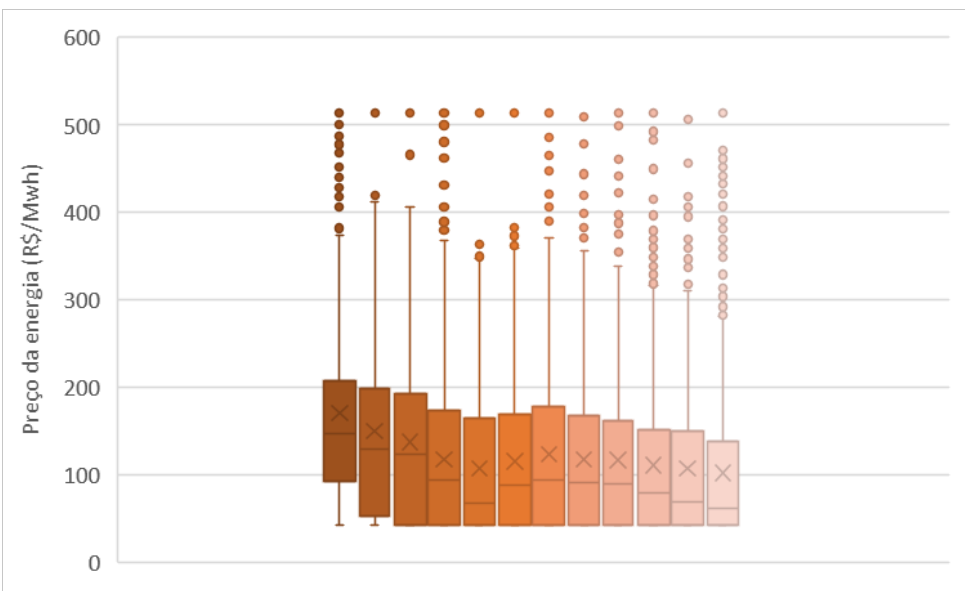

Figura 4.3: Distribuição de preços spot esperados por mês para o ano de 2020 - Dados de agosto/2019. Fonte: Elaboração Própria.

níveis de aversão ao risco entre os agentes que transacionam no mercado futuro (Bessembinder \& Lemmon, 2002).

Observa-se também uma variância nos dados estimados para os mesmos meses em diferentes anos (figuras 4.1 e 4.2) e até mesmo para o mesmo período, mas obtidos em momentos diferentes (figuras 4.1 e 4.3). No primeiro caso é compreensível que existam diferenças entre os anos em análise, uma vez que as séries hidrológicas que alimentam o modelo oferecem uma projeção multianual. No segundo caso a diferença pode ser causada por novos dados observados que são incorporados nas séries de energia natural afluente, atualizando as estimativas futuras.

O perfil histográfico de cada mês é diferente entre si. Para evitar repetir as informações já observada nos gráficos de distribuição acima, serão apresentados os histogramas de dois meses selecionados, janeiro e dezembro de 2020, nos dados obtidos em agosto de 2019. 

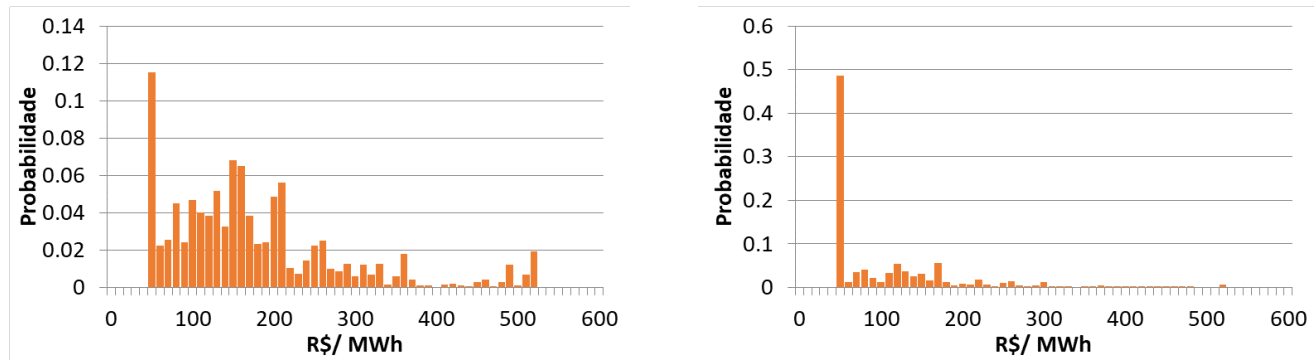

Figura 4.4: Histograma de preços spot esperados para janeiro (esq.) e dezembro (dir.) de 2020 - Dados de agosto/2019. Fonte: Elaboração Própria.

Outros dados de entrada utilizados para o treinamento e a validação do modelo são as projeções de curva forward feitas por especialistas e obtidas através da DCide. Na tabela 4.1 estão dispostos os valores das curvas forward e também a média anual de cada conjunto de dados de preço, de modo a compará-los.

Tabela 4.1: Preços forward e preço futuro anual médio usados no modelo.

\begin{tabular}{|l|c|c|c|}
\hline Série & $\begin{array}{c}\text { Preço forward } \\
\text { (DCide - R\$/MWh) }\end{array}$ & $\begin{array}{c}\text { Preço spot médio } \\
\text { (ONS - R\$/MWh) }\end{array}$ & Obtenção \\
\hline Ano 2020 & 199,32 & 97,56 & jan $/ 2019$ \\
Ano 2021 & 179,26 & 79,25 & jan $/ 2019$ \\
Ano 2020 & 192,75 & 122,92 & ago $/ 2019$ \\
\hline
\end{tabular}

Observa-se para os dados expostos na tabela 4.1 uma diferença considerável entre a média do preço spot esperado e o preço forward, indicando que os agentes deste mercado não são neutros ao risco.

\section{2}

\section{Treinamento e validação do modelo para o algoritmo 1}

Utilizando os dados de treinamento através da planilha de fluxo de caixa descrita no capítulo anterior para o primeiro algoritmo de modelagem aversa ao risco foram obtidos os parâmetros para a função ECP_G com dois níveis de aversão ao risco, para o comprador e o vendedor. Foram estimadas, portanto, quatro parâmetros para cada agente, totalizando oito parâmetros, que estão dispostos na forma de tabela e na forma de equação, abaixo.

Tabela 4.2: Parâmetros otimizados na calibração do algoritmo 1

\begin{tabular}{|lc|c|c|c|c|}
\cline { 2 - 6 } \multicolumn{1}{c|}{} & $\lambda_{0}$ & $\lambda_{1}$ & $\lambda_{2}$ & $\alpha_{1}$ & $\alpha_{2}$ \\
\hline Comprador & 0,47 & 0,21 & 0,32 & 0,40 & 0,99 \\
Vendedor & 0,04 & 0,39 & 0,57 & 0,94 & 0,99 \\
\hline
\end{tabular}




$$
\left\{\begin{array}{l}
E C P \_G_{C}=0,47 E[X]+0,21 C V a R_{40}(X)+0,32 C V a R_{99}(X) \\
E C P \_G_{V}=0,04 E[X]+0,39 C V a R_{94}(X)+0,57 C V a R_{99}(X)
\end{array}\right.
$$

Estes resultados indicam uma maior sensibilidade ao risco por parte do vendedor do contrato por diferenças, o que é esperado uma vez que o preço spot futuro possui forte assimetria (desvio para a esquerda) e cauda pesada (leptocurtose). Isto também reflete a premissa teórica de disparidade dos níveis de aversão de risco entre os agentes (Benth et al., 2008).

Também são fornecidas, para fim de ilustração os resultados financeiros, de utilidade e de equivalente certo da simulação que obteve os parâmetros ótimos. Estes estão descritos na tabela 4.3.

Tabela 4.3: Resultados financeiros da calibração do modelo

\begin{tabular}{|lc|c|c|}
\cline { 2 - 4 } \multicolumn{1}{c|}{} & $\begin{array}{c}\text { VPL médio } \\
\text { (milhões de Reais) }\end{array}$ & Utilidade & $\begin{array}{c}\text { Equivalente Certo } \\
\text { (milhões de Reais) }\end{array}$ \\
\hline Comprador & -87 & -110 & -98 \\
Vendedor & 87 & -151 & -98 \\
\hline
\end{tabular}

Durante o treinamento do modelo foi necessário obter a utilidade associada a cada série de fluxo de caixa simulado. Estes valores foram utilizados para determinar o trecho da curva em que o equivalente certo de cada agente é calculado. A partir dos dados de utilidade, ao contrastá-los com o resultado financeiro (VPL) do fluxo de caixa, obtemos gráficos empíricos semelhantes ao gráfico teórico apresentado na figura 2.3, para cada agente. A distribuição do resultado do VPL e os níveis de utilidade associados à função subjacente ao ECP_G podem ser vistas na 4.5 e na 4.6 abaixo.

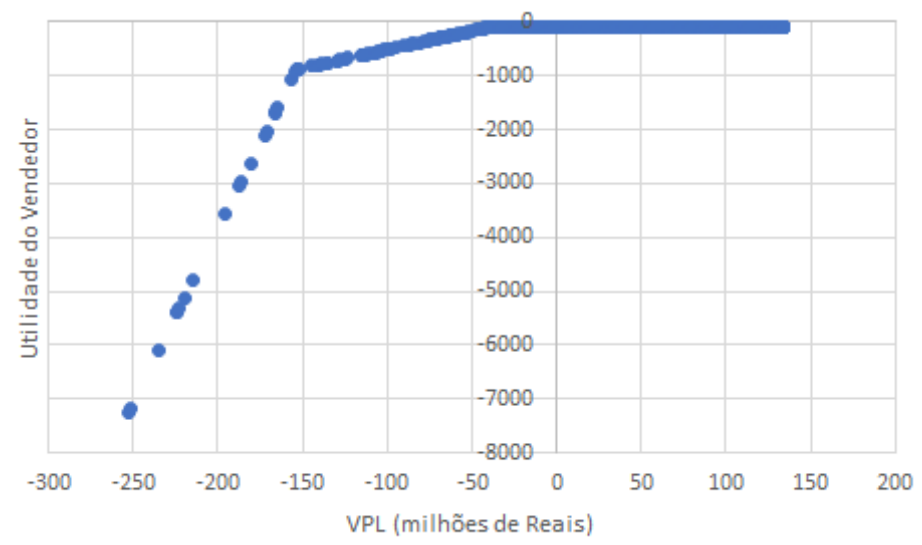

Figura 4.5: Função de utilidade subjacente à medida ECP_G para o vendedor. Fonte: Elaboração Própria. 


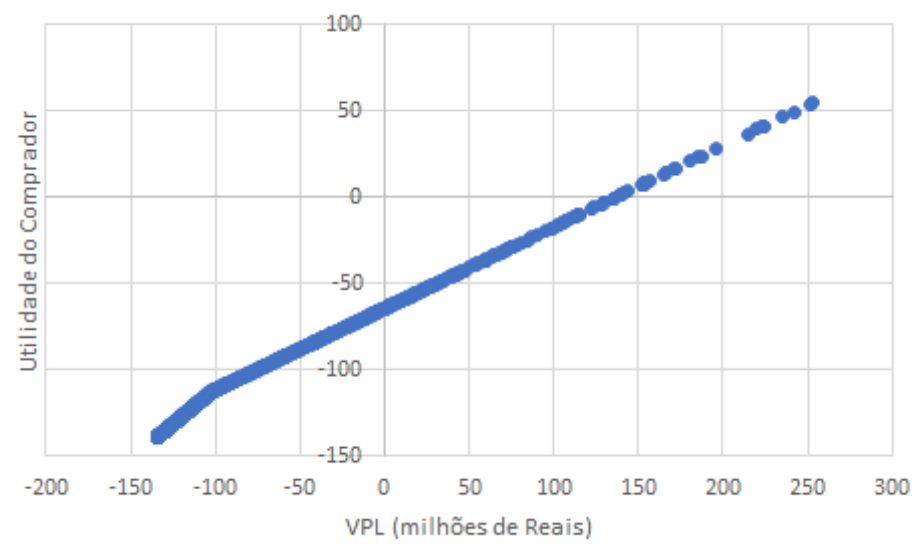

Figura 4.6: Função de utilidade subjacente à medida ECP_G para o comprador. Fonte: Elaboração Própria.

A curva de utilidade do vendedor apresenta os pontos de corte em $V a R_{\alpha_{1}}=-41$ e $V a R_{\alpha_{2}}=-153$, ambos os valores expressos em milhões de Reais. A curva do comprador apresenta os pontos de corte em $V a R_{\alpha_{1}}=-102$ e $V a R_{\alpha_{2}}=-134$ milhões de Reais. O terceiro segmento da curva de aversão ao risco do comprador não pode ser visualizada pois nenhum resultado financeiro ficou abaixo do ponto de corte inferior. Isso pode ser explicado pelo limite de preço mínimo que oferece um sólido piso para o preço, o que oferece maior proteção ao comprador de CfD, em geral o vendedor de eletricidade.

Para encontrar o resultado da otimização dos parâmetros de aversão ao risco das equações de utilidade dos agentes é preciso partir de um preço de contrato de referência. Uma pesquisa interessante é observar como o resultado financeiro de cada agente e seu equivalente certo se comportam para diferentes valores do preço de equilíbrio. Em uma programação simples utilizando Visual Basic for Applications no Excel, foram obtidos os valores correspondentes de VPL e equivalente certo para cada agente. Estes podem ser vistos na figura 4.7.

É possível observar uma relação linear entre o preço de contrato e o VPL, e também uma relação linear entre o preço de contrato e o equivalente certo. Estes resultados poderiam ser intuídos a partir das equações apresentadas no capítulo anterior, e são empiricamente visualizados na figura. O equilíbrio que foi calculado no modelo pode ser observado no gráfico no encontro entre as linhas do comprador e do vendedor. No caso neutro ao risco o equilíbrio é idêntico à média do preço spot esperado, conforme demonstrado analiticamente. No caso avesso ao risco, onde o equilíbrio é dado pelo equivalente certo, obtemos o valor de 199,32 R\$/MWh, que corresponde à curva forward obtida em janeiro, que é o valor utilizado para o treinamento do modelo.

Utilizando as equações 4-1 obtidas no passo de treinamento do modelo sobre os dados de validação obtidos no final de agosto de 2019, foi obtido o 


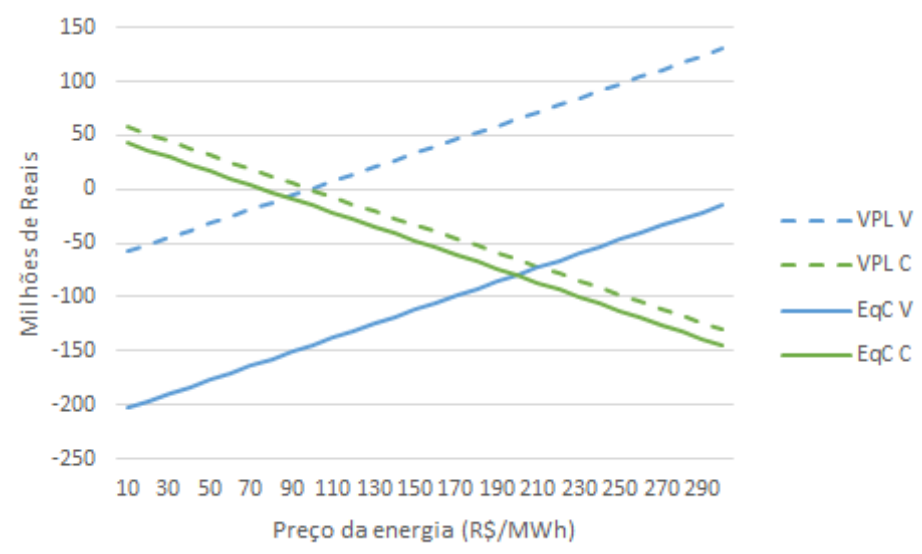

Figura 4.7: Análise do VPL e equivalente certo para cada nível de preço de contrato. Fonte: Elaboração Própria.

preço de equilíbrio para o caso avesso ao risco no valor de 218,39 $\mathrm{R} \$ / \mathrm{MWh}$, ao passo que a expectativa dos especialistas previa o valor de 192,75 R \$/MWh.

A segunda validação realizada utiliza também os mesmos parâmetros otimizados na seção anterior sobre os dados de validação obtidos em janeiro de 2019 para o ano de 2021. Neste caso o preço de equilíbrio é de 163,50 R $\$ / \mathrm{MWh}$, e a expectativa dos especialistas era de 179,26 R\$/MWh.

O erro de estimação no primeiro caso foi de $13,3 \%$ e no segundo caso de $8,8 \%$ em valores absolutos. Não é, sem dúvida um valor desprezível, porém considerando-se que a alimentação do modelo é exclusivamente dada por séries de preços spot futuros, podemos comparar a performance deste algoritmo com a estimativa trivial da média do preço spot futuro.

Pode-se observar para os dois conjuntos de dados de validação que o modelo oferece um valor de previsão mais próximo da curva forward do que a média dos preços spot futuros. Este é um resultado que está alinhado com a premissa teórica de que a função ECP_G captura a aversão ao risco dos agentes.

\section{3}

\section{Treinamento e validação do modelo para o algoritmo 2}

O segundo algoritmo utilizado para calcular os preços forward utiliza as equações desenvolvidas no capítulo anterior para encontrar o preço de equilíbrio a cada mês, e posteriormente calcular o seu valor médio anual.

De forma semelhante ao que foi feito na validação do algoritmo 1, o treinamento do modelo partirá de um preço de contrato fixado no valor da estimativa do preço forward, obtido em janeiro de 2019 para o ano de 2020. Os parâmetros de aversão ao risco para cada agente são obtidos através da 
otimização com limites, utilizando a ferramenta Solver do Excel.

Os parâmetros otimizados neste algoritmo são diferentes dos que estão apresentados para o algoritmo 1, e serão expostos na tabela e equação a seguir.

Tabela 4.4: Parâmetros otimizados na calibração do algoritmo 2

\begin{tabular}{|lc|c|c|c|c|}
\cline { 2 - 6 } \multicolumn{1}{c|}{} & $\lambda_{0}$ & $\lambda_{1}$ & $\lambda_{2}$ & $\alpha_{1}$ & $\alpha_{2}$ \\
\hline Comprador & 0,09 & 0,32 & 0,59 & 0,61 & 0,97 \\
Vendedor & 0,15 & 0,46 & 0,39 & 0,95 & 0,98 \\
\hline
\end{tabular}

$$
\left\{\begin{array}{l}
E C P_{C}=0,09 E[X]+0,32 C V a R_{61}(X)+0,59 C V a R_{97}(X) \\
E C P_{V}=0,15 E[X]+0,46 C V a R_{95}(X)+0,39 C V a R_{98}(X)
\end{array}\right.
$$

Os resultados das validações e treinamentos dos algoritmos 1 e 2, bem como os erros de estimativa, estão apresentados nas tabela 4.5 e 4.6.

Tabela 4.5: Resultados da validação dos algoritmo 1 e 2 - preços de equilíbrio em R $\$ / M W h$

\begin{tabular}{|ll|cccc|}
\hline Série PLD & Uso & Forward & Méd. PLD & Algo. 1 & Algo. 2 \\
\hline Jan/19 A+1 & Treino & 199,32 & 97,56 & 199,32 & 192,66 \\
Jan/19 A+2 & Valid. & 179,26 & 79,25 & 163,50 & 163,71 \\
Ago/19 A+1 & Valid. & 192,75 & 122,92 & 218,39 & 203,78 \\
\hline
\end{tabular}

Tabela 4.6: Erros de estimativa do preço médio de equilíbrio para o preço forward em percentual.

\begin{tabular}{|l|ccc|}
\hline Série PLD & Média PLD & Algoritmo 1 & Algoritmo 2 \\
\hline Jan/19 A+2 & $-55,8$ & $-8,8$ & $-8,7$ \\
Ago/19 A+1 & $-36,6$ & 13,2 & 5,7 \\
\hline
\end{tabular}

Embora seja mais simplificado no cálculo, os resultados apresentados pelo algoritmo 2 são no mínimo tão bons quanto os obtidos com o algoritmo 1. Este segundo algoritmo tem ainda a vantagem de calcular o equilíbrio de maneira analítica, e uma vez obtidos os parâmetros otimizados para as curvas de utilidade, o preço de equilíbrio é o resultado de uma equação de equilíbrio, não havendo necessidade de utilizar métodos de chegada como o Atingir Meta, utilizado no algoritmo 1.

Outra vantagem do algoritmo 2 é que o cálculo do equilíbrio mensal permite a visualização das estimativas discretas do modelo para cada mês do período em análise. Isso pode ser visualizado graficamente e é possível observar a diferença entre os preços do modelo e a média dos preços futuros a cada mês, 


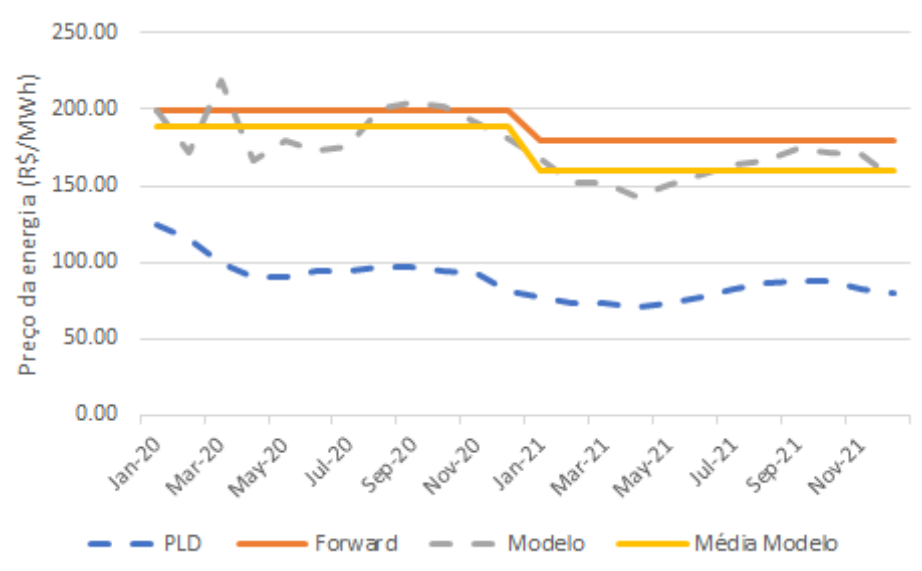

Figura 4.8: Preços de equilíbrio mensal para 2020 e 2021 calculados a partir dos dados de treinamento e validação. Fonte: Elaboração Própria.

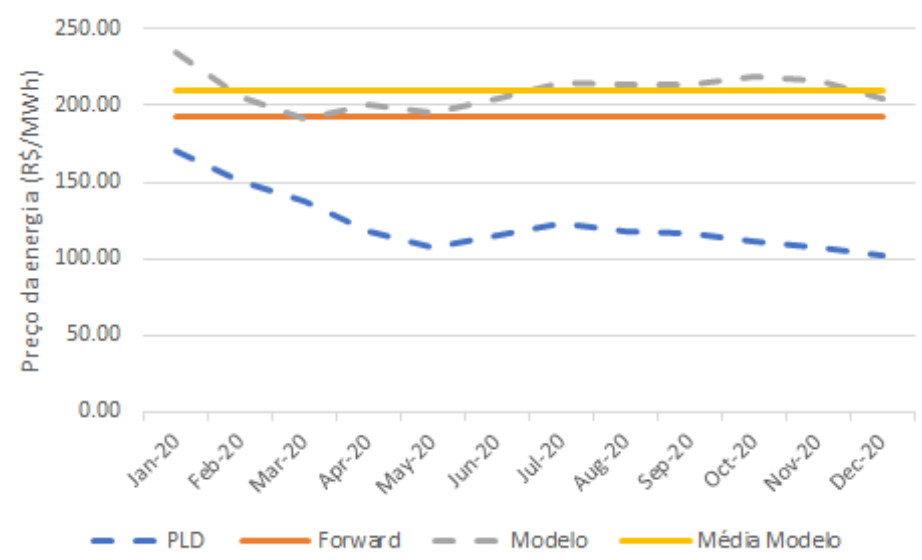

Figura 4.9: Preço de equilíbrio mensal para 2020 calculado a partir dos dados de validação. Fonte: Elaboração Própria.

ilustrando o efeito da aversão ao risco. Os resultados discretos para cada rodada de validação estão expostos nas figuras 4.8 e 4.9 .

Observe-se que como o preço de contrato no algoritmo 2 é a média do preço de equilíbrio mensal, mesmo no treinamento o preço de contrato não é idêntico ao preço forward.

A principal diferença observada entre os parâmetros otimizados nos algoritmos 1 e 2 são os pesos para a medida de aversão ao risco do comprador. Essa diferença pode ser compreendida pela análise de cada um dos componentes da equação de equilíbrio que será feita na seção de sensibilidade realizada ao final deste capítulo. Explicando de forma sucinta, em função da distribuição dos preços mensais, os valores de CVaR entre 60 e 100 são, na maioria dos casos para o comprador, idênticos entre si. Isto ocorre em função da prevalência do preço mínimo nos dados observados, como pode ser observado por exemplo no histograma da esquerda na figura 4.4. São poucos os meses que não apre- 
sentam essa concentração nos valores mínimos, como por exemplo é visto no histograma da direita nesta mesma figura.

Assim, para a maioria dos casos há pouca ou nenhuma diferença entre o efeito dos dois termos de CVaR para o comprador. Estes termos acabam existindo apenas pois foram forçados na especificação do modelo. Testes utilizando apenas um parâmetro de aversão ao risco para o comprador foram realizados na confecção deste trabalho e oferecem resultado satisfatório. Os resultados não foram incluídos apenas para não aumentar desnecessariamente a complexidade deste estudo, mas serão vistos na seção seguinte.

\section{4}

\section{Análise de sensibilidade dos parâmetros otimizados}

Com o intuito de compreender o efeito de cada termo de aversão ao risco no equilíbrio geral, foram realizados testes de sensibilidade utilizando os dados de treinamento do modelo, isto é, os dados obtidos em janeiro de 2019 para o ano de 2020. Todos os testes desta seção utilizam as fórmulas de equilíbrio desenvolvidas para o algoritmo 2. Nos gráficos a seguir os pesos $\lambda_{1}$ e $\lambda_{2}$ são gradativamente adicionados no modelo, de forma independente, tanto para o comprador, quando para o vendedor.
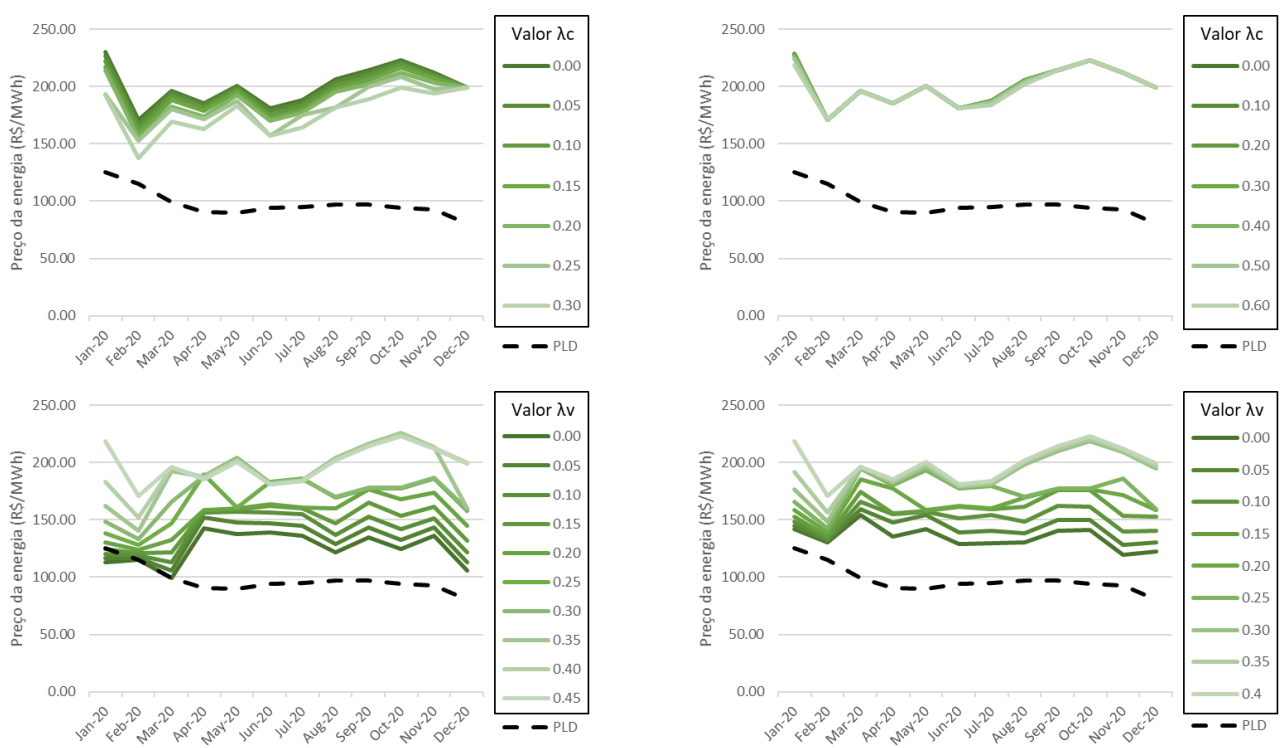

Figura 4.10: Sensibilidade para $\lambda_{1}$ (esq.) e $\lambda_{2}$ (dir.) do comprador e do vendedor - Dados de janeiro/2019. Fonte: Elaboração Própria.

Pode-se perceber que o comportamento de cada termo afeta o equilíbrio de forma diferente. Em particular, como observado no gráfico superior à direita da figura 4.10 o efeito de $\lambda_{2}$ é marginal e serve apenas como ajuste fino no modelo. Isto foi observado na seção anterior quando tratando dos diferentes pesos observados para o comprador entre os algoritmos 1 e 2. Para visualizar 
isto, será conferido peso nulo para o segundo termo de aversão ao risco do comprador, ou seja $\lambda_{2 C}=0$, e uma nova sensibilidade para $\lambda_{1 C}$ será obtida. Esta pode ser observada na figura 4.11.

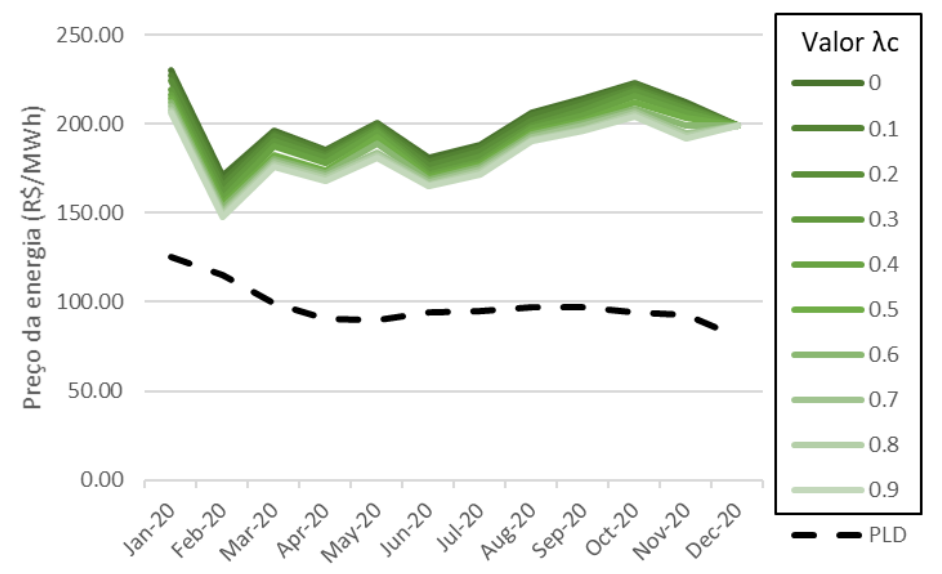

Figura 4.11: Sensibilidade para $\lambda$ do comprador no modelo com um único nível de risco - Dados de janeiro/2019. Fonte: Elaboração Própria.

A estimativa dos preços mensais utilizando apenas um peso $\lambda$ para o comprador, contra os dois pesos utilizados para o vendedor pode alcançar valores compatíveis com o da previsão de especialistas, o que confirma a possibilidade de encontrar uma otimização satisfatória com esta configuração. Este resultado será visto novamente a frente, quando o modelo for simplificado para utilizar a função ECP ao invés da ECP_G no teste de sensibilidade.

Outra maneira de visualizar o efeito dos pesos $\lambda$ é analisar seu impacto diretamente sobre o preço médio de equilíbrio. Neste caso poderemos utilizar as duas dimensões para os pesos de cada agente, como pode ser visto nos gráficos de superfície expostos na figura 4.12 .
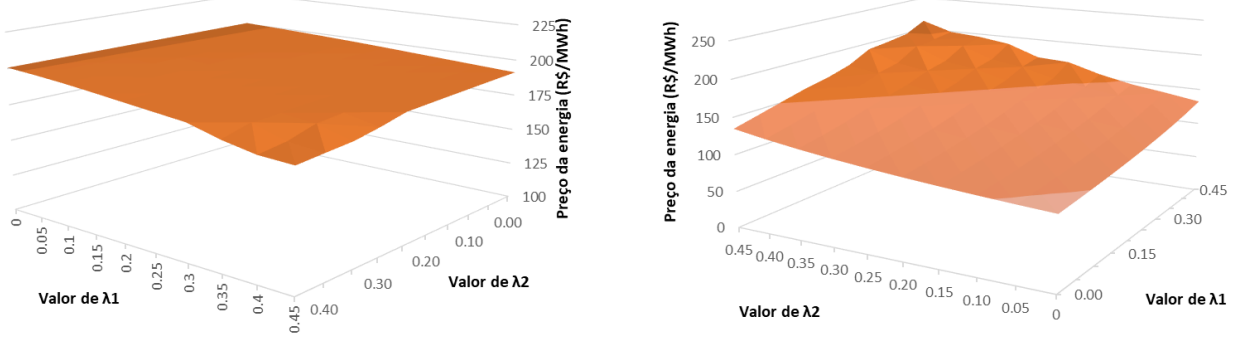

Figura 4.12: Gráfico de superfície para $\lambda_{1}$ e $\lambda_{2}$ para o comprador (esq.) e o vendedor (dir.) - Dados de janeiro/2019. Fonte: Elaboração Própria.

Com o intuito de testar também a necessidade do segundo termo de aversão ao risco para ambos os agentes, o modelo com apenas um termo de aversão foi testado. Neste caso ao invés de usar a função ECP_G, usa-se a 
função ECP original, com apenas um termo $\lambda$ para cada agente. Abaixo estão descritas as equações usadas neste modelo.

$$
\left\{\begin{array}{l}
E C P_{C}=\left(1-\lambda_{C}\right) \times E[X]+\lambda_{C} \times C V a R_{\alpha_{C}}(X) \\
E C P_{V}=\left(1-\lambda_{V}\right) \times E[X]+\lambda_{V} \times C V a R_{\alpha_{V}}(X)
\end{array}\right.
$$

Ao contrário do que foi feito nos gráficos de sensibilidade expostos acima para o modelo das seções anteriores, neste modelo ECP testaremos o efeito de cada parâmetro de aversão isoladamente, ou seja, como se o agente que está na contraparte fosse neutro ao risco. Deste modo é possível observar o efeito de cada termo no deslocamento da curva de preço spot futuro.
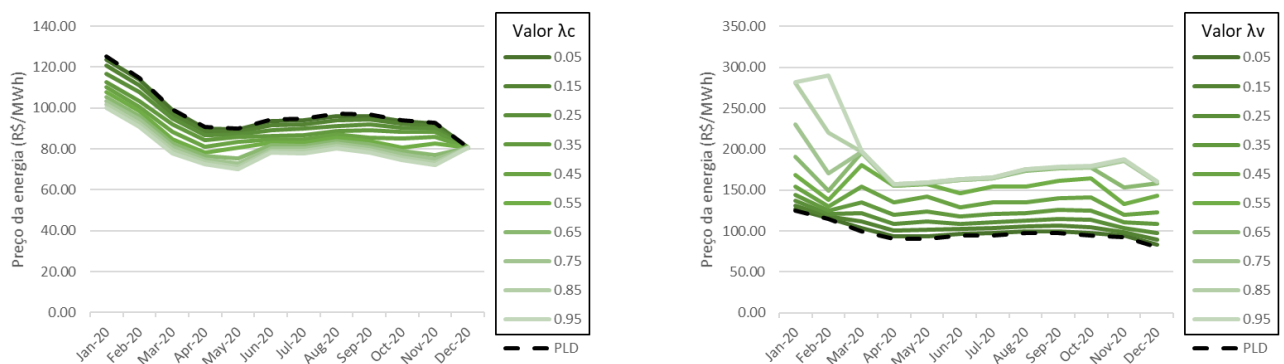

Figura 4.13: Efeito de $\lambda_{C}$ e $\lambda_{V}$ sobre a média do PLD - Dados de janeiro/2019. Fonte: Elaboração Própria.

O efeito do peso $\lambda$ no modelo que utiliza a função ECP, como ilustrado na 4.13 corresponde à intuição econômica: quanto maior for a ponderação da aversão ao risco do agente comprador, menor será seu preço de contrato, uma vez que este termo tem sinal negativo no cálculo de seu resultado financeiro. O inverso é observado para o vendedor, que possui interesse em negociar um menor preço de contrato para se beneficiar mais de um futuro aumento de preços.

Outro teste relevante é realizar a sensibilidade para o nível de aversão ao risco, $\alpha$. Como o modelo utiliza apenas um termo de aversão ao risco para cada agente é possível utilizar as duas dimensões do gráfico e visualizar o efeito da interação entre os parâmetros $\alpha$ e $\lambda$ simultaneamente sobre o preço médio de equilíbrio.

No gráfico do vendedor, no lado direito da figura 4.14, é possível observar que o preço forward determinado pelos especialistas não é atingido mesmo com os parâmetros mais pesados de aversão ao risco. Isso demonstra que para o vendedor não é possível obter um preço de equilíbrio compatível com as previsões de mercado utilizando apenas um termo de aversão ao risco. Este teste, ao ser realizado no início da confecção deste trabalho, mostrou que o 

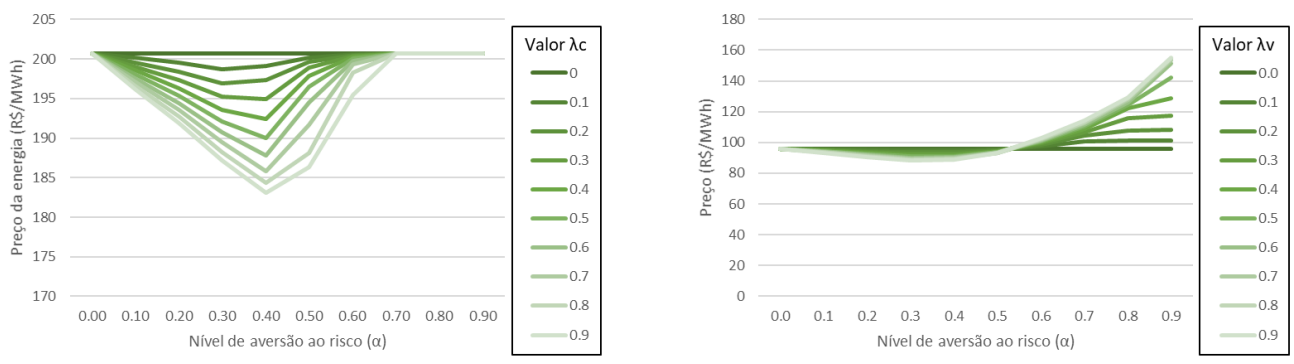

Figura 4.14: Sensibilidade para $\lambda$ e $\alpha$ no modelo com um único nível de risco - Dados de janeiro/2019. Fonte: Elaboração Própria.

modelo mínimo para o equilíbrio possui dois termos de aversão, e necessita, portanto, da função ECP_G.

O gráfico abaixo reforça este achado. Mantendo o comprador com apenas um termo de aversão ao risco, e fixando o segundo termo de aversão ao risco para o vendedor em $\lambda_{2 V}=0,4$ e $\alpha_{2 V}=0,98$, conforme os pesos obtidos no treinamento do algoritmo 1 , foi feito o mesmo teste de sensibilidade para $\lambda_{1 V}$ e $\alpha_{1 C}$ visto na figura anterior. O resultado, que pode ser visualizado na figura 4.15, mostra claramente que o preço de equilíbrio de $199 \mathrm{R} \$$ /MWh pode ser alcançado por este modelo.

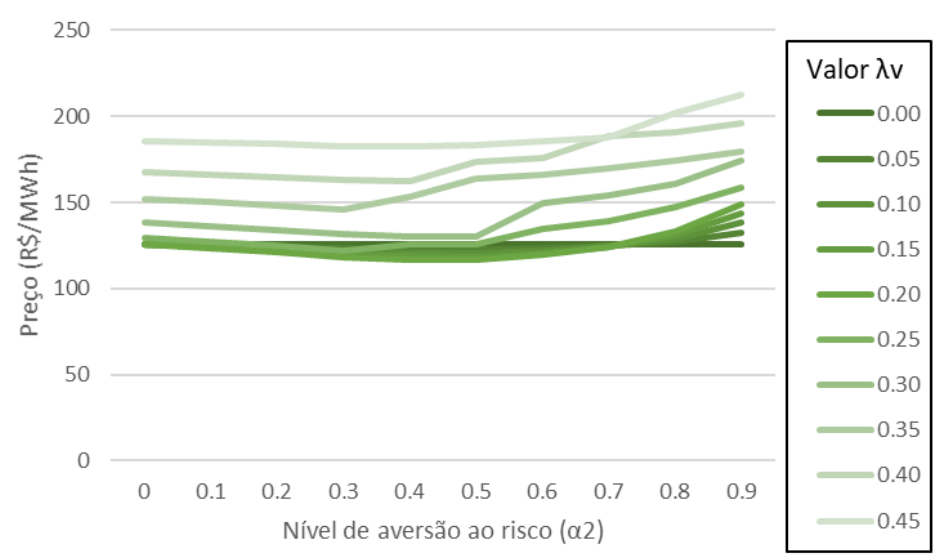

Figura 4.15: Sensibilidade para $\lambda_{2}$ e $\alpha 2$ do vendedor - Dados de janeiro/2019. Fonte: Elaboração Própria.

Para finalizar foi realizada um teste de sensibilidade do preço de equilíbrio para o primeiro algoritmo nos dois períodos de validação do modelo. Pode ser observado na figura 4.16 abaixo que o efeito da taxa de remuneração de capital do fluxo de caixa é muito pequeno, sendo praticamente irrelevante dada a precisão do modelo. As diferentes trajetórias do preço de equilíbrio nos dois cenários se deve à média das séries de PLD no primeiro mês da amostra ser menor do que a média de todo o período no caso dos dados de janeiro, e o oposto no caso dos dados de agosto. Isso implica que a taxa de remuneração de capital 
tem efeito prático de priorizar o equilíbrio no curto prazo em detrimento do equilíbrio de todo o período. A escolha do valor ótimo para taxa de desconto de capital foge ao escopo deste trabalho.
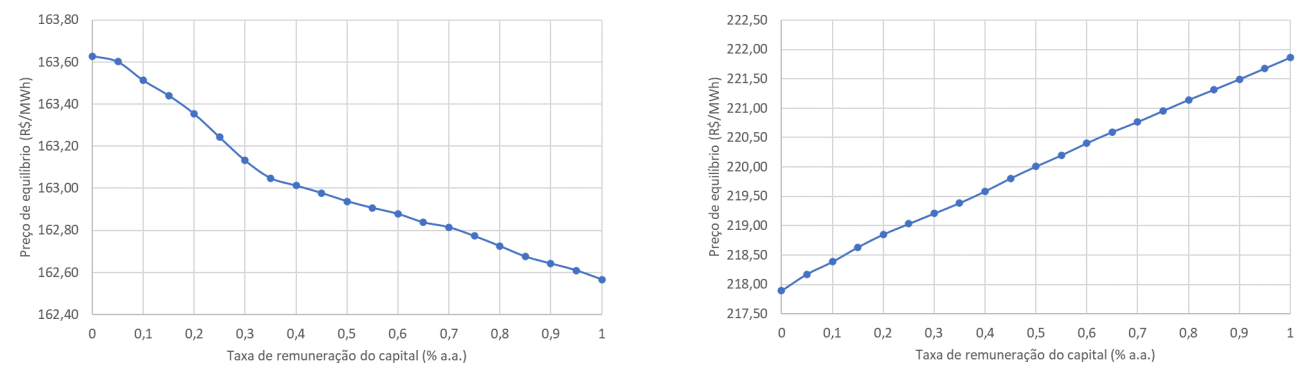

Figura 4.16: Sensibilidade do preço de equilíbrio para diferentes taxas de remuneração de capital. Dados de janeiro/2019 à esquerda e agosto/2019 à direita. Fonte: Elaboração Própria.

Os testes realizados nesta seção demonstram que o modelo que utiliza a função ECP_G é ao mesmo tempo parcimonioso e simétrico, oferecendo o menor número de termos de aversão ao risco que atinge os valores de previsão compatíveis com os analistas de mercado, ao mesmo tempo que não faz distinção prévia entre os agentes em relação ao formato de suas preferências. 


\section{5}

\section{Conclusão e trabalhos futuros}

Neste trabalho foram propostos dois algoritmos distintos para obter um preço de equilíbrio que emule o preço forward da energia elétrica para o mercado brasileiro. Para alcançar estes resultados foi utilizado o contrato por diferenças, um derivativo financeiro que possui as peculiaridades de prover boa exposição ao ativo subjacente, com pouca necessidade de capital alocado e cálculo de resultado simples.

Demonstrou-se que o mercado futuro de eletricidade pode ser representado pela interação entre dois agentes teóricos, transacionando em posições opostas e utilizando o contrato por diferenças, quer seja este agente um especulador ou um participante do mercado. Esta demonstração confere abrangência ao resultado obtido, e embora o intuito deste trabalho seja o de contribuir academicamente, consideramos que um modelo semelhante ao que está aqui descrito poderia ser utilizado na economia real.

O resultado alcançado pelo modelo é satisfatório e apresenta pequena margem de erro, considerando-se que a única informação utilizada são os preços spot esperados - dado amplamente disponível entre os participantes do mercado futuro de eletricidade. Se comparado com o resultado da média dos preços spot esperados, o modelo apresenta significativa diminuição dos erros de estimativa, frente a previsão de especialistas do mercado.

Embora o resultado do modelo completo tenha sido obtido por simulação e otimização, utilizando o software Excel e a ferramenta Solver, soluções equivalentes foram obtidas através de um segundo algoritmo desenvolvido analiticamente de forma original neste trabalho. As equações expostas na seção de metodologia foram também utilizadas para realizar a sensibilidade do modelo e são de fácil cálculo e interpretação.

Através dos testes realizados demonstrou-se que, embora não exista a necessidade de um segundo termo de aversão ao risco para o comprador, a sua permanência não afeta o resultado do modelo. Para manter a simetria entre os agentes foi utilizada a mesma função utilidade para ambos, permitindo diferentes parâmetros de aversão. Em contrapartida foi demonstrado que um modelo com apenas um termo de aversão ao risco para o vendedor não oferece resultados compatíveis com o mercado e não deve ser utilizado para o propósito desta estimação. Desta maneira confirmou-se a relevância da utilização da função ECP_G, escolhida para este trabalho.

Os resultados aqui obtidos podem ser aperfeiçoados através de sua 
aplicação em uma base maior de dados. Uma limitação relevante é a provável inadequação dos pesos otimizados para o mercado real, dada o restrito conjunto de séries em que os modelos foram treinados e validados. Assim, reforça-se que o objetivo do trabalho é oferecer uma estrutura original de cálculo do preço de equilíbrio que sirva como uma aproximação do preço forward para o mercado elétrico. Os resultados empíricos aqui obtidos servem apenas em caráter ilustrativo e não pretendem ser definitivos.

Outra limitação imediatamente identificável é a restrição do modelo aos dados de preço spot futuros, sem levar em consideração outras informações que podem ser efetivamente utilizadas pelos agentes do mercado para formar suas expectativas. Estas outras fontes de informação podem ser adicionadas em uma forma estendida do modelo em trabalhos futuros e fogem ao escopo pretendido com este exercício.

Uma solução simples e eficaz para o cálculo do preço forward da energia elétrica poderia ser aplicada em diferentes soluções dentro e fora do mercado futuro. Ferramentas analíticas de uso comum poderiam oferecer maior transparência e segurança para os agentes do mercado e todos os demais que estão expostos às flutuações temporais do preço da eletricidade. É a intenção deste autor que esta publicação ofereça uma módica contribuição para este fim. 


\section{6 \\ Referências bibliográficas}

BENTH, F. E.; CARTEA, Á. ; KIESEL, R.. Pricing forward contracts in power markets by the certainty equivalence principle: Explaining the sign of the market risk premium. Journal of Banking and Finance, 32(10):2006-2021, 2008. 4.2

BESSEMBINDER, H.; LEMMON, M. L.. Equilibrium pricing and optimal hedging in electricity forward markets. Journal of Finance, 57(3):1347-1382, 2002. 1, 4.1

BROWN, C.; DARK, J. ; DAVIS, K.. Exchange traded contracts for difference: Design, pricing, and effects. Journal of Futures Markets, 30(12):1108-1149, dec 2010. 4, 3.1, 3.2

CCEE. InfoPLD no. 382 - 4a. semana de janeiro/2019. CCEE, 2019. Acesso em: Março de 2020. 1

DCIDE ENERGIA. Como utilizar o boletim semanal da curva forward. DCide LTDA, 2018. Acesso em: Março de 2020. 1.1

EPE. Balanço energético nacional 2019. Empresa de Pesquisa de Energia, 2019. 1.1

FERKINGSTAD, E.; LØLAND, A.. Coping with area price risk in electricity markets: Forecasting Contracts for Difference in the Nordic power market. arXiv preprint arXiv:1406.6862, p. 1-29, 2014. 3.1 .1

FERNANDES, G.; GOMES, L. L. ; BRANDÃO, L. E. T.. A risk-hedging tool for hydro power plants. Renewable and Sustainable Energy Reviews, 90(May 2017):370-378, 2018. 1.1

FERNANDES, G.; LIMA GOMES, L. ; TEIXEIRA BRANDÃO, L. E.. Mitigating Hydrological Risk with Energy Derivatives. Energy Economics, 81:528-535, 2019. 1.1

FLETEN, S. E.; LEMMING, J.. Constructing forward price curves in electricity markets. Energy Economics, 25(5):409-424, 2003. 1

HULL, J.; TREEPONGKARUNA, S.; COLWELL, D.; HEANEY, R. ; PITT, D.. Fundamentals of futures and options markets. Pearson Higher Education AU, 2013. 1.1 
JORION, P.. Risk2: Measuring the risk in value at risk. Financial analysts journal, 52(6):47-56, 1996. 3

KLOTZLE, M. C.; GOMES, L. L.; BRANDÃO, L. E. T. ; FIGUEIREDO PINTO, A. C.. Desenvolvimento de uma Medida de Desempenho Comportamental. Brazilian Review of Finance, 10(3):395, 2012. 1

KRISTIANSEN, T.. Pricing of Contracts for Difference in the Nordic market. Energy Policy, 32(9):1075-1085, 2004. 3.1.1

LUZ, C. P. D. M. S.. Cristina Pimenta de Mello Spineti Luz Otimização comercial de um parque eólico no Brasil utilizando simulação de Monte Carlo com variáveis climáticas exógenas e uma nova função de preferência Otimização comercial de um parque eólico no Brasil utilizando s. PhD thesis, PUC-Rio, 2016. 1

LUZ, C. P. D. M. S.; GOMES, L. L. ; BRAndÃO, L. E. T.. Analysis of the Dynamics of the Brazilian Forward Market of Electricity. Review of Business Management, p. 314-334, 2012. 1, 1.1

MARCKHOFF, J.; WIMSCHULTE, J.. Locational price spreads and the pricing of contracts for difference: Evidence from the Nordic market. Energy Economics, 31(2):257-268, 2009. 3.1.1

ONIFADE, T. T.. Hybrid renewable energy support policy in the power sector: The contracts for difference and capacity market case study. Energy Policy, 95:390-401, 2016. 3.1.1

PELAJO, J. C.; BRANDÃO, L. E.; GOMES, L. L. ; KLOTZLE, M. C.. Wind farm generation forecast and optimal maintenance schedule model. Wind Energy, 22(12):1872-1890, 2019. 1.1

PFLUG, G. C.. Some Remarks on the Value-at-Risk and the Conditional Value-at-Risk. In: PROBABILISTIC CONSTRAINED OPTIMIZATION, p. 272-281. Springer, 2000. 3

ROCKAFELLAR, R. T.; URYASEV, S.. Optimization of conditional value-at-risk. The Journal of Risk, 2(3):21-41, 2000. 3

ROUTLEDGE, B. R.; SEPPI, D. J. ; SPATT, C. S.. The "Spark Spread": An Equilibrium Model of Cross-Commodity Price Relationships in Electricity. Working paper, p. 38, 2001. 1 
SCHUR, R.; GÖNSCH, J. ; HASSLER, M.. Time-consistent, risk-averse dynamic pricing. European Journal of Operational Research, 277:587-603, 2019. 3

STREET, A.. On the Conditional Value-at-Risk probabilitydependent utility function. Theory and Decision, 68(1-2):49-68, 2010. 2

StREet, A.; BARROSO, L. A.; GRANVILle, S. ; PEREIRA, M. V.. Bidding strategy under uncertainty for risk-averse generator companies in a long-term forward contract auction. In: 2009 IEEE POWER \& ENERGY SOCIETY GENERAL MEETING, p. 1-8. IEEE, jul 2009. 2

URYASEV, S.. Conditional value-at-risk: optimization algorithms and applications. In: PROCEEDINGS OF THE IEEE/IAFE/INFORMS 2000 CONFERENCE ON COMPUTATIONAL INTELLIGENCE FOR FINANCIAL ENGINEERING (CIFER) (CAT. NO.00TH8520), p. 49-57. IEEE, 2000. 3

WELISCH, M.; POUDINEH, R.. Auctions for allocation of offshore wind contracts for difference in the UK. Renewable Energy, 147:12661274, 2020. 3.1.1

WERON, R.. Electricity price forecasting: A review of the state-ofthe-art with a look into the future. International Journal of Forecasting, 30(4):1030-1081, 2014. 2 